\title{
EVALUATION OF A SEAFLOOR NUCLEAR POWER SUPPLY AND ITS POTENTIAL APPLICATIONS
}

FINAL REPORT

Submitted to the

\section{DIVISION OF NUCLEAR RESEARCH} AND APPLICATIONS, ENERGY RESEARCH AND DEVELOPMENT ADMINISTRATION CONTRACT NO. EY-76-C-02-4123

Arthur D.Little, Inc. 


\section{DISCLAIMER}

This report was prepared as an account of work sponsored by an agency of the United States Government. Neither the United States Government nor any agency Thereof, nor any of their employees, makes any warranty, express or implied, or assumes any legal liability or responsibility for the accuracy, completeness, or usefulness of any information, apparatus, product, or process disclosed, or represents that its use would not infringe privately owned rights. Reference herein to any specific commercial product, process, or service by trade name, trademark, manufacturer, or otherwise does not necessarily constitute or imply its endorsement, recommendation, or favoring by the United States Government or any agency thereof. The views and opinions of authors expressed herein do not necessarily state or reflect those of the United States Government or any agency thereof. 


\section{DISCLAIMER}

Portions of this document may be illegible in electronic image products. Images are produced from the best available original document. 


\title{
EVALUATION OF A SEAFLOOR NUCLEAR POWER SUPPLY AND ITS POTENTIAL APPLICATIONS
}

\author{
FINAL REPORT
}

Submitted to the

\begin{abstract}
DIVISION OF NUCLEAR RESEARCH
AND APPLICATIONS,

ENERGY RESEARCH AND DEVELOPMENT ADMINISTRATION

CONTRACT NO. EY-76-C-02-4123
\end{abstract}

by

ARTHUR D. LITTLE, INC.

CAMBRIDGE, MASSACHUSETTS

Case No. 79947

April 30, 1977

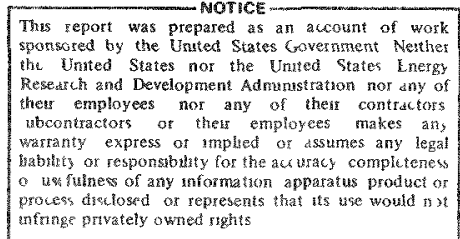

process distiosed or represents that its are wostd on

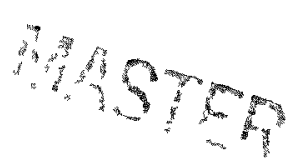

Arthur D. Little, Inc. 


\section{NOTICE}

This report was prepared as an account of work sponsored by the United States Government. Neither the United States nor the United States Energy Research and Development Administration, nor any of their employees, nor any of their contractors, subcontractors, or their employees, makes any warranty, express or implied, or assumes any legal liability or responsibility for the accuracy, completeness, or usefulness of any information, apparatus, product or process disclosed or represents that its use would not infringe privately owned rights. 


\section{ACKNOWLEDGMENTS}

In the course of this program, the staff of Arthur D. Little, Inc. have received information, assistance and advice from many sources. I take this opportunity to express our appreciation to all of those individuals and organizations who have helped.

Mr. Norman Gerstein, Division of Nuclear R\&D, Energy Research and Development Administration

Mr. A.B. Martin, Atomics International Division, Rockwell International, Canoga Park, California

Mr. H.A.J. Koster, Lockheed Petroleum Services, Ltd. Vancouver, B.C., Canada

Exxon Production Research Company, Houston, Texas

Mobil Research and Development Corporation, Dallas, Texas

Atlantic Richfield Company, Dallas, Texas

Gulf Research and Development Company, Pittsburgh, Pennsylvania

Getty Oil Company, Los Angeles, California

Chevron Oil Company, San Francisco, California

Union Oil Company, Research Department, Brea, California

Sundstrand Corporation, Rockland, Illinois

Simplex Wire and Cable Company, Portsmouth, New Hampshire

Deep Oil Technology, Inc, Long Beach, California

Reda Pump Division of TRW, Inc., Bartlesville, Oklahoma

Electro-Motive Division, General Motors Corporation, La Grange, Illinois

Solar Division (Gas Turbines), International Harvester Corporation, San Diego, California

Wabash Power Equipment Company, Wheeling, Illinois

United States Geological Survey, Interior Department, Menlo Park, California

Within Arthur D. Little, Inc., the following staff members deserve special recognition for their efforts in this study.

Dr. James Nicol - Program Review

Dr. Richard S. Stone - Nuclear Engineering

Mr. Bradford B. Underhill - Program Review

Dr. E. George Pollak - Marine Engineering

Ms. Andrea S. Reyman - Marine Engineering

Mr. John J. Cawley - Marine Engineering

Mr. Edward G. Schwarm - Electrical Engineering

Dr. Bette M. Winer - Electrical Engineering

Dr. A.A. Fowle - Mechanical Engineering

Mr. Frederik W. Mansvelt-Beck - Petroleum Engineering

Mr. Bruce M. Putnam - Petroleum Engineering

Mr. James A. Monk - Petroleum Engineering

Mrs. Sandra J. Caputo merits particular commendation for secretarial assistance in preparing this report.

John J. Bzura

Case Leader 
BLANK 


\section{ABSTRACT}

The seafloor nuclear power supply (SNPS) concept has been proposed by Atomics International (AI) and Lockheed Petroleum Services, Ltd. (LPS) as a source of electrical energy for subsea pumping of petroleum products. It consists of a small nuclear reactor, moderated by zirconium hydride $(\mathrm{ZrH})$ and cooled by liquid metal $(\mathrm{NaK})$, which drives a $3 \mathrm{MW}$ turbine/generator system using toluene as the working fluid. Arthur D. Little, Inc., was selected to assess the technical and economic feasibility of a SNPS, and to determine if potential applications for a SNPS might exist in offshore oil field development schemes where conventional power supplies could not be used.

We have determined that the concept is technically feasible, with regard to the nuclear, marine, electrical and petroleum engineering aspects. However, its initial cost of $\$ 14$ million and operating expenses of $\$ 900,000$ per year ${ }^{1}$ are considerably more in each case than the costs of conventional alternative power supplies. For the type of field development proposed as an example by LPS, a combination of gas turbines and dc cables would cost about $\$ 8$ million. Fuel in the form of gas from the wells would be available at near-zero cost in almost all cases of field development, so that operating expenses would be minimal. Other power supply and cable systems were investigated, up to lengths of 200 miles. Alternating current systems are preferred at distances less than 20 miles; direct current is more economical at greater distances.

We were unable to discover any set of circumstances in which oil field development is likely to occur and for which the SNPS offers uniquely attractive capabilities.

1. Arthur D. Little, Inc., estimates. 


\section{BLANK}




\section{Page}

List of Tables $\quad$ ix

List of Figures $\quad x i$

I. SUMMARY AND CONCLUSIONS

INTRODUCTION

A. REVIEW OF THE SUMMARY REPORT 1

B. OFFSHORE OIL PRODUCTION 3

C. COMPETITIVE ALTERNATIVES TO THE SNPS

D. CONCLUSIONS 5

11. REVIEW AND UPDATE OF AI/LPS REPORTS 7

A. TECHNICAL REVIEW 7

B. ECONOMIC REVIEW 17

III. OFFSHORE OIL PRODUCTION 33

A. CURRENT PRACTICE 33

B. GEOGRAPHICAL AREAS OF INTEREST WITHIN THE UNITED STATES

C. FUTURE TECHNOLOGY 42

IV. COMPETITIVE ALTERNATIVES TO THE SNPS 47

A. PLATFORM/VESSEL-MOUNTED POWER SUPPLIES 47

B. SHORE-BASED POWER SUPPLIES 48

C. CABLE POWER TRANSMISSION SYSTEMS

APPENDIX 1: REFERENCES

APPENDIX 2: AI EXPERIENCE WITH REACTORS USING INTERNAL CONTROL RODS

APPENDIX 3: ELECTROMAGNETIC PUMP DATA 61

APPENDIX 4: AI's PROPOSED REFUELING BASE

APPENDIX 5: POWER SUPPLY COST BREAKDOWN 91 


\section{BLANK}




\section{LIST OF TABLES}

Table No.

Page

I Deep Water Corrosion Rates of Structural Materials

10

II Comparison Between SNAP Reactors and Proposed Subsea

Nuclear Power System

12

III Income Statements - ADL Estimates

28

IV Gulf of Mexico Petroleum Potential

35

V Pacific Coast Petroleum Potential

36

VI Alaskan Offshore Petroleum Potential

39

VII

Atlantic Coast Petroleum Potential

41

VIII Turbine/Generator System Data (1977 \$)

49

IX

Diesel/Generator System Data (1977 \$)

49

$\mathbf{X}$

Description of Cable Systems

51

XI

Cable Systems Data: 3.0 MW Delivered to Load

52 
BLANK 


\section{LIST OF FIGURES}

Figure No. $\quad$ Page

$1 \quad$ Unit Residual Value of Gulf Coast Oil Production 24

2 Cash Flows - ADL, Inc. Estimates 27

$3 \quad$ Map of Alaska and Adjacent Seas 37

4 Sketch of 1500 Foot Compliant Tower 43

$5 \quad$ Tension Leg Platform 44 


\section{SUMMARY AND CONCLUSIONS}

\section{INTRODUCTION}

This study was carried out to determine the technical feasibility and potential uses of a seafloor nuclear power supply (SNPS) in developing offshore oil fields. The SNPS concept has been proposed by Atomics International $(\mathrm{AI})^{1}$ as a source of electrical energy which would power an oil pumping station located nearby on the sea bottom. Lockheed Petroleum Services, Ltd. (LPS $)^{2}$, has worked in conjunction with AI on developing a combined barge/base system for the SNPS unit which would provide both transportation capability and a base on the sea bottom.

AI described the complete SNPS system ${ }^{3}$ and a hypothetical field development example in a report entitled "Summary, Introduction and Application of Nuclear Power Stations in Subsea Production of Oil and Gas." We will simply refer to this document as the summary report in the discussion which follows. Both AI and LPS provided supporting documents for the summary report. "The Application of a Compact Nuclear Power System to Subsea Oil Production," from AI, described the nuclear engineering aspects in greater detail. LPS concentrated on transport and emplacement techniques at sea in their report, "Installation and Periodic Recovery of Subsea Nuclear Power Stations." These documents were released in mid-1974.

The primary questions addressed in this study were as follows:

1. Is the concept of a small, unattended nuclear-powered generator technically feasible for use on the sea floor?

2. Are the cost estimates realistic?

3. What are the characteristics of conventional power sources and cable systems that would be competitive alternatives?

4. Are there potential SNPS applications in oil field development where conventional alternatives could not be employed?

Arthur D. Little, Inc. was also asked to review and update the summary report. The remainder of this section summarizes our findings relevant to these questions and the review.

\section{A. REVIEW OF THE SUMMARY REPORT}

This report began with a discussion of the potential for offshore oil production in the future, and how the SNPS unit might assist in developing such areas. Brief descriptions of the proposed reactor, power system and barge/base followed. An economic analysis of field development for a large hypothetical oil field in the Gulf of Mexico completed the document. Our review did not follow this particular arrangement, but was organized into a technical review of the proposed systems and an economic analysis based on 1977 data. The potential for offshore oil production is discussed in subsection $B$.

1. Atomics International, located in Canoga Park, California, is a division of the Rockwell international Corporation.

2. LPS is headquartered in Vancouver, B.C., and is a subsidiary of Lockheed Aircraft Corporation.

3. The SNPS consists of a small reactor fueled with enriched uranium and moderated by zirconium hydride $(\mathrm{ZrH})$, driving a $3 \mathrm{MW}$ turbine-generator system using toluene as the working fluid. 


\section{Nuclear Engineering}

The Arthur D. Little, Inc. review of the proposed SNPS reactor design included an analysis of fuel elements, the control system, shielding and the primary power loop components. In addition to the two AI reports mentioned previously, Atomics International provided us with eight other documents (see Appendix 1) pertaining either to the parent SNAP reactor program or proposed SNPS designs. Midway through our review, we met with them at their headquarters to discuss potential problem areas.

From our analysis of this material, we have concluded that the design is feasible; however, we believe that additional development attention should be directed toward the following items:

- Fuel element performance (minimize swelling)

- Consideration of flux and temperature peaking in the core

- Performance of serpentine concrete shield under irradiation

- Testing of control rod drive units

\section{Mechanical/Thermal Engineering}

As described in Section II, AI has experience with liquid metal $(\mathrm{NaK})^{4}$ coolants for nuclear reactors. They have also built $\mathrm{NaK} / \mathrm{NaK}$ and $\mathrm{NaK} / \mathrm{H}_{2} \mathrm{O}$ heat exchangers. The Sundstrand Corporation, which would manufacture the toluene turbine, ${ }^{5}$ has accumulated data on hot gas/toluene heat exchangers, but no firm has experience with $\mathrm{NaK} /$ toluene heat exchangers (boilers). The critical nature of this component in the power conversion system mandates an ultra-reliable design. It is our opinion that the $\mathrm{NaK} /$ toluene boiler may require more design and development effort than anticipated.

\section{Petroleum and Marine Engineering}

The components and procedures suggested by LPS for subsea oil production should be appropriate and satisfactory, with one exception: the proposed pumping station. This would be a very complex device, and is crucial with regard to keeping oil (hence revenues) flowing. Despite this fact, relatively little effort has been spent on optimization of its performance (through detailed design work). We suggest that this component should receive additional design input to minimize manned maintenance visits and optimize remote control capabilities. After all, why must a SNPS be designed for four years of operation without manned attention if the pumping station requires attention twice a year?

Several minor points were raised in the analysis of LPS' proposed barge/base assembly, of which winch operational capability after four years of immersion is an example. The barge/base is still in the conceptual design phase, but we believe that this integral part of the SNPS system is well-engineered based on currently available plans and data from LPS.

4. NaK is a mixture of sodium and potassium that will remain liquid at room temperature.

5. See Section II.A.4 for details. 


\section{Economic Analysis of Fleld Development}

LPS had presented a hypothetical field development example in the summary report, which showed that production using a SNPS was potentially quite profitable. They calculated an internal rate of return of approximately $50 \%$ on a $\$ 190$ million investment using oil revenues of $\$ 5$ per barrel.

Our first comment was that the size of the field, located in the Gulf of Mexico, was very much larger than an "average" field in this area ${ }^{6}$ We then adjusted most of the component costs upward, made more realistic assumptions about field production volume in the final years, and performed an independent economic analysis using present-worth techniques. This demonstrated that the potential rate of return without consideration of bonus payments was satisfactory at $39^{\prime}$. As discussed in Section II, however, we would expect that bonus payments for the leased area would drive the rate of return down to a traditional $15-20 \%$.

In conclusion, the economic analysis performed here is helpful in terms of understanding the investments and cash flows of oil field development; it was not done to focus on SNPS cost versus the cost of competitive alternatives. Our analysis of this direct comparison appears in Section IV.

\section{B. OFFSHORE OIL PRODUCTION}

\section{Current Practice}

In this subsection, we described the current procedures used by oil companies in field development and some of the attitudes related to deep $(\geq 600$ foot depths) offshore and arctic development. The basic approach is conservative, i.e. to use extensions of proven technology if possible. Logically enough, they plan to develop as much of the "easier" offshore areas as possible before tackling arctic offshore regions.

\section{Geographical Areas of Interest}

We investigated the four U.S. offshore areas with regard to how fields would probably be developed in each area, and whether a SNPS would have a competitive advantage over conventional power systems in any area. Emphasis was given to the Gulf of Mexico, since it is the largest offshore production area at present, and to Alaskan waters (particularly the arctic offshore areas) which have the largest potential petroleum finds. The extreme difficulty of developing arctic offshore areas (at depths greater than 50-60 feet) where ice is a major problem was discussed at length. We raised the possibility that arctic offshore fields less than "giant" sized (500 million barrels of reserves) might not be developed at all under certain conditions.

\section{Future Technology}

The two concepts of major importance to future oil field development are advanced platforms and subsea production systems. It is anticipated that these concepts, taken together, will enable oil companies ultimately to develop offshore fields in depths as great as 3000 feet. we discussed Exxon's approach, consisting of a guyed or compliant tower, and the tension-leg platform developed by Deep Oil Technology, Inc.

6. See Section II.B regarding this point. 
Several companies are working on seafloor production components, for both distributed systems (wells dispersed over the field) and template systems (all wells through a common base). Prototypes of each system exist and are currently undergoing tests.

Based on our interviews with oil company personnel, we believe that these advanced platform concepts coupled with conventional cable systems would be preferred to a SNPS unit if subsea power was required to develop the field.

\section{COMPETITIVE ALTERNATIVES TO THE SNPS}

In performing this analysis, we confirmed a point regarding fuel for conventional power plants that was tentatively raised in early meetings with AI and LPS. It became evident that a suitable fuel could be taken or made from a very small fraction of the well output in almost any circumstance of field development. Gas would quite probably be available, and require minimal physical treatment before use in turbines. Alternatively, small "refineries" could be set up easily at remote locations to supply low-grade gasoline and/or diesel fuel. Thus the problems of massive fuel storage tanks and fuel transportation in bulk to remote locations could be avoided altogether.

As a result of the technical and economic analysis performed in Section II, we determined that additional development activity would be required if a SNPS were to be commercialized. It is our conclusion that the final SNPS cost will be at least $\$ 14$ million, or $\$ 4,700 / \mathrm{kW}$. Our estimate of fuel and operating cost was $\$ 900,000$, on an equivalent annual expense basis. These capital and operating costs were used to compare the SNPS with conventional alternative systems.

Both turbine-powered and diesel-powered generating units are available in "packaged" form from reliable suppliers at prices on the order of $\$ 200 / \mathrm{kW}$ in the $2000-3000 \mathrm{~kW}$ range. Depending on fuel quality, they can be expected to run for up to three years before requiring major maintenance. All the systems we considered had at least two separate primemover/generator units, so that an output of nominally $3 \mathrm{MW}$ could be maintained continuously.

For those scenarios where oil is pumped to a terminal on shore, the most economical approach to supplying pumping power consists of a dual-transformer substation and a dc cable system. This assumes that a local utility can tie in to the substation, of course; otherwise, the preceding power supplies would be used.

Part of our efforts were focused on defining and analyzing cable systems which would be capable of delivering $3 \mathrm{MW}$ to the load with high reliability. Both ac and dc systems were considered, over distances ranging from 5 miles to 200 miles. The latter figure is not an upper limit to length, however; it simply corresponds to a total cost considerably greater than the anticipated SNPS cost of $\$ 14$ million. We concluded that ac systems were preferred for distances less than 20 miles, and dc systems for this and greater distances. Tables X and XI in section IV summarize the systems in terms of components, cost and operating parameters.

A "conventional" power supply system as defined in this report consists of an energy source (prime mover plus generator or substation) and a cable system. Our primary conclusion is that a conventional power supply system would be substantially cheaper to buy, and quite probably cheaper to operate, than a SNPS unit for any realistic 40 -mile field development scheme. As

7. See Section II for derivation of these costs. 
discussed in section IV, the specification of $50,000 \mathrm{BOPD}^{\mathrm{a}}$ and a $3 \mathrm{MW}$ power rating sffectively limit the single-phase pumping distance to the neighborhood of 40 miles. Analyses could certainly be made using other flow rates, pipeline distances, pumping requirements (number of pumping stations and locations) and power requirements, but we believe conventional systems would be superior.

\section{CONCLUSIONS}

We have been unable to discover any set of circumstances in which oil field development is likely to occur and for which the SNPS offers uniquely attractive features.

In summary, our analysis indicates that a conventional generator and cable system capable of supplying $3 \mathrm{MW}$ to the pumping station would be cheaper in terms of total capital cost than a SNPS for distances of approximately 100 miles or less. Furthermore, we have found that fuel for these conventional power plants (such as gas turbines and diesels) would usually be available at near-zero cost in any realistic oil field development scheme. This implies that fuel cost would be minimal compared to $\$ 900,000$ per year for the SNPS. Therefore, we conclude that a SNPS is not economically competitive with conventional systems either in terms of capital cost or operating cost for any realistic oil field development scheme.

8. Barrels of oll per day. 
BLANK 


\section{REVIEW AND UPDATE OF AI/LPS REPORTS}

\section{A. TECHNICAL REVIEW}

\section{Introduction}

The following comments apply primarily to the Atomics International (AI) document entitled "Summary, Introduction and Application of Nuclear Power Stations in Subsea Production of Oil and Gas." This report is supported in turn by "The Application of a Compact Nuclear Power System to Subsea Oil Production," AI-74-20, and "Installation and Periodic Recovery of Subsea Nuclear Power Stations," LPS-188, from Lockheed Petroleum Services, Ltd. (LPS). All three reports were completed in 1974 .

The summary report briefly discusses the hypothesized need for a seafloor nuclear power supply (SNPS) in relation to future offshore oil production, the design requirements of such a supply, advantages of parent SNAP reactor technology and the proposed methods and equipment for transporting, emplacement and servicing of the reactor. The main SNPS components are a nuclear reactor cooled by liquid metal (NaK), a $\mathrm{NaK}$ to toluene heat exchanger, a toluene vapor turbine and a generator rated at $3 \mathrm{MW}$. These power system components are mounted on a barge/base structure which provides transport capability and serves as a base on the sea floor.

Much of the summary report, particularly those paragraphs describing current engineering approaches to problems of interest, is satisfactory from a technical viewpoint. These portions, therefore, require little comment from us. Most of our comments will be directed toward those areas where we believe additional effort may be required in developing the SNPS reactor.

\section{Marine Engineering}

In general, the hardware and procedures proposed for the transportation and emplacement of a SNPS unit by LPS are appropriate for the tasks involved. The demonstrated capability of LPS to emplace and service their prototype subsea completion system in the Gulf of Mexico provides strong support for the proposed SNPS barge/base system and operating procedures. In the following paragraphs, we have singled out a small number of potential problem areas or items which may require additional development effort for the SNPS concept to be commercialized.

The two topics of this study which are significantly dependent on top-quality marine engineering are A) subsea petroleum production systems and B) the barge/base unit of the seafloor nuclear power supply. Fortunately, subsea well head completions and associated production equipment such as flowline bundles with remote connection capability and manifold centers are in what might be termed the "advanced prototype" phase of development. LPS, the SEAL" group, EXXON, the Cameron Iron Works, Vetco and Deep Oil Technology ${ }^{2}$ are firms which either currently offer subsea completion equipment or have development programs underway. We believe it is reasonable to assume that these companies will continue to develop more advanced and/or economical subsea completion equipment. The driving force will be improved economics in developing deep-water fields (depth 600 feet). Consequently, from this point on it will be assumed that all necessary subsea completion equipment will be available when the SNPS units might become commercially available.

1. SEAL stands for Subsea Equipment Associates, Ltd., which originally consisted of Mobil Oil Corp., Westinghouse Electric Corp., British Petrcleum Corp., Compagnie Francaise Des Petroles and Group DEEP.

2. DOT Is a unit of the FLUOR Corporation. 
As proposed by AI and LPS, the reactor and power conversion modules will be built into a seaworthy barge. This barge will mate with an encircling base, which is capable of automatic descent and emplacement on the sea floor. Once the base is in position, the barge would be winched down and secured into the base.

\section{The Barge}

Our reaction to the barge stability statement in the summary report, "unit will have stability in 100 knot wind conditions" is that such a claim cannot be strongly supported on the basis of current engineering status. The proposed SNPS barge/base is still entirely in the conceptual phase. However, the concept seems feasible and LPS will be able to build upon experience gained in constructing a large barge/base for installation in Brazil later this year.

The barge design as planned has an open well where the reactor module is placed. This seems potentially hazardous, in that a possibility exists for the reactor module to be struck by a rock and damaged if the barge happens to run aground on a rocky shoal or coast. Protection should be added across the open well bottom to rule out this potential hazard.

We have some reservations about the long-term performance of the barge winches. The problem becomes worse in direct proportion to depth. Although the report specifies that the winches will be "... oil-filled with pressure compensation for all operating parts" additional information on how this pressure compensation will be carried out is needed. If a gas is involved, then either A) the seals must be extraordinarily good, essentially permitting zero leakage, or B) an appreciable supply of gas must be available to make up for seal losses during the four years of operation. Furthermore, the winch lines themselves (Dupont's Fiber B has been proposed) should be examined in more detail. For example, it should be proven that marine growth will not cause deterioration of the lines over their anticipated operating life.

The countermeasures described in Section 3.3., which would be taken in the event that both down-haul lines break as the base is lowered, do not seem adequate. If both lines break, then it is quite likely the remote control cable would be parted also. In this case, divers would be required to recover the base. However, even if the control cable can be paid out fast enough to prevent breakage the procedures described are not satisfactory. An uncontrolled return to the surface caused by "blowing" the tanks remotely is a proposal counter to basic precautions of salvage or other undersea operations. If the base were to strike the underside of the reactor barge during such an ascent, it is possible the reactor module would be damaged.

\section{Cost versus Depth}

Figure 5.2 of LPS-188 portrays marine hardware cost versus water depth in feet, with the slope of the curve decreasing continuously as one goes from 400 to 2,000 feet and remaining fairly constant out to 3,200 feet. LPS has defended this cost-versus-depth characterization with the following points:

1. that ballast is usually required to counteract positive buoyancy for depths up to roughly 3,000 feet, and that material would be shifted from ballast to extra wall thickness relatively easily; and

2. that higher rated hull strengths can be achieved by designing to a stricter code, and incorporating spacial alloy steels, if necessary, at only slightly greater cost. 
The definition of marine hardware (paragraph 5.2 of LPS-188) - seems to include the barge/base, pressure vessels, heat exchangers, cables and connecting devices, and appurtenances. Many of these items are non-standard, and must be designed specifically for the SNPS program. In addition to normal developmental costs, there will be costs associated with testing, certification and system integration. We believe that carrying out such a program rigorously and comprehensively will cost significantly more at greater design depths. Unfortunately, we can not be more quantitative given the hypothetical nature of the concept. Our concluding remark on this topic is that the curve showing cost versus water depth should be regarded as the lower limit of potential cost, which might be achieved if develepment proceeds as smoothly as envisioned by LPS.

\section{Fouling}

When a structure is placed in sea water, marine organisms invariably become attached to it and may thrive. Bio-fouling can be a serious problem in that it generally accelerates the rate of corrosion and in the case of power source heat exchangers could seriously reduce design heat transfer efficiency. In fact, it can be expected that the rate at which fouling accumulates would be enhanced by the higher temperature water in immediate contact with the heat exchanger surfaces. As a result, unless the materials and design are carefully selected, corrosion would be accelerated and heat exchanger life shortened.

Of the several classes of alloys listed in Table I that show low corrosion rates, only the copper-nickel alloys remain relatively free of bio-fouling. This is because the $\mathrm{Cu}-\mathrm{Ni}$ alloys corrode fast enough to release copper in corrosion products at a rate in excess of about 1 mil per year. Since 1945 many investigators have demonstrated that the iron modified 90-10 Cu-Ni and the 70$30 \mathrm{Cu}-\mathrm{Ni}$ alloys provide a good combination of anti-fouling properties and resistance to pitting in the ocean environment. These $\mathrm{Cu}-\mathrm{Ni}$ alloys should be candidate materials for the heat exchanger surfaces.

Bio-fouling should not prove to be a major problem on other structural surfaces in deep water, because the rate of growth is slow due to decreasing oxygen concentration with depth. LPS has found little evidence of fouling on their wellhead cellars installed at 300 foot depths in the Gulf of Mexico. Furthermore, most sensitive and movable elements are to be placed inside the one atmosphere chamber. A possible exception might be the seals around hatches and shrouds where docking takes place; these surfaces should be designed to remain free of plant growth and corrosion over the life cycle of the system (20 years).

\section{Nuclear Engineering}

In our review of the proposed design for a $3 \mathrm{MW}$ zirconium hydride moderated nuclear reactor, as described in AI-74-20, we determined that many components planned for this reactor incorporate significant changes from previous SNAP reactor components. The component differences arise from the fact that the proposed SNPS reactor is not a simple, straightforward extrapolation of a SNAP reactor; rather, the SNPS concept is a completely new reactor and power generating system which does rely heavily on many elements of SNAP technology. In the following discussion we will establish which components or concepts are novel and in need of additional attention, which are extensions of previous technology, and which are essentially identical to previous SNAP counterparts. 
TABLE |

DEEP WATER CORROSION RATES OF STRUCTURAL MATERIALS

\section{Structural Material}

1. Carbon and Low Alloy Steels

2. Aluminum Alloys

3. Stainless Steels

4. Nickel Base Alloys

5. Copper Base Alloys

6. Titanium Alloys

\section{Corrosion Rate In Mils Per Year}

$$
1 \text { to } 10
$$

10 to 160

1 to 5

$<1$

$<1$

$<1$

\section{Comment}

Uniform corrosion

Pitting corrosion is major difficulty; severely reduces tensile strength

Pitting and crevice corrosion are major difficulties; corrosion protection required

Inconel 625 and Hastelloy -C provide excellent corrosion performance

90-10 and 70-30 CU-Ni alloys have excellent performance in seawater; also inhibit organic growth and fouling*

Some susceptibility to stress corrosion cracking; low susceptibility to uniform or localized corrosion

Clearly, structural materials must be chosen carefully for use in bottom-mounted structures. Because the costs of maintenance and repair are high over the life span of such equipment, a high first cost of materials can generally be justified.

*The acceptance of these alloys may be questionable in some areas from an environmental viewpoint. 
The previous SNAP fuel material was enriched uranium (93 weight $\%$ U-235) combined with zirconium hydride (the neutron moderator). This mixture was vacuum melted and extruded into solid cylindrical rods of various lengths and diameters, to meet the particular requirements of each reactor in the SNAP program. It should be emphasized at this point that the advanced SNAP reactors (SNAP-8 and SNAP-10A series) were designed to high performance goals, so that both fuel and cladding were subjected to high temperatures and stresses. As a consequence of this approach, which pushed then-current technology to its limits, many fuel elements failed in service when placed in experimental SNAP reactors. This was particularly true for the S8ER, where $80 \%$ of the elements developed cracks in the Hastelloy cladding. Performance improved in the S8DR which followed, but $34 \%$ of the fuel elements developed cracks in this reactor which operated between 1100 and $1300^{\circ} \mathrm{F}$ (peak coolant outlet temperature).

It was concluded from these experiments that fuel swelling caused the cladding cracks, and that swelling occurred from excessively high fuel temperatures. Consequently, AI proposed considerably lower operating temperatures for the SNPS reactor. Based on SNAP-2 data and irradiation tests of fuel elements, they are of the opinion that fuel swelling will not be a problem in the SNPS reactor because the maximum fuel temperature will be approximately $64 \%$ of that encountered in the SNAP- 8 reactor. ${ }^{3}$

Although AI proposed a new fuel production process in AI-74-20, which would have used a cast fuel element, they have now concluded that the original extrusion process is most appropriate for the SNPS program at this time. We agree with this decision, and also with the proposal that the casting process may be investigated in the future as a cost-reduction item.

Other differences related to fuel include the use of $\mathrm{NaK}$ inside the cladding to promote heat transfer between fuel and cladding ( $\mathrm{NaK}$ bonding), substitution of stainless steel for Hastelloy cladding, and some form of turbulence generator (fins or wire wrap) on the cladding to improve heat transfer. We see no cause for concern regarding these changes from previous SNAP technology. The final change to be discussed is fuel element configuration. Previous one-piece fuel rods (SNAP-8) exhibited bowing due to fuel swelling. AI now proposes to use segmented fuel in an attempt to eliminate bowing, specifically seven 4-inch segments of $\mathrm{U}-\mathrm{ZrH}$ instead of a single 28inch length within the cladding. Our comment on this approach is that even with segmentation, fuel swelling may produce localized stresses on the cladding as opposed to uniform bowing stresses. AI has done work on stress distributions arising from various fuel segment conditions (see AI-AEC-13077), notably angular misalignment between segments, and stated that stresses are within satisfactory limits (for these conditions). However, additional data showing that bowing of the 4 inch segments is not likely to produce excessive stress on the cladding would be reassuring.

These changes, as well as others yet to be discussed, are summarized in Table II. As shown in this table, a completely new control system is planned for the SNPS system. This system is altogether different from the neutron reflector control system used in SNAP reactors. The primary consequence of using a "rodded core" for the proposed SNPS reactor is that calculations of local flux and temperature peaking factors are considerably more difficult than was the case for

3. The previous peak radial average temperature was $\sim 1500^{\circ} \mathrm{F}$; SNPS fuel would run at $965^{\circ} \mathrm{F}(\mathrm{see}$ Al document ER652-120-001). 
Table II

COMPARISON BETWEEN SNAP REACTORS AND PROPOSED SUBSEA NUCLEAR POWER SYSTEM

\section{SUBSYSTEM COMPONENT}

- Individual fuel elements

- Fuel bonding

- Fuel cladding

$\ddot{N}$ element assembiy

- Control

\section{PREVIOUS DESIGN}

Single rod

Ceramic coating

He vacuum

Hastelloy $-\mathrm{N}$

Fins or wire wrap

on stainless steel

cladding

72 elements per fuel assembly, one control rod in center, hexagonal shape $6 "$ across flats

Reflector control
$19 \mathrm{~B}_{4} \mathrm{C}$ in-core rods
REASON FOR CHANGE

COMMENTS

Fuel element bowing

and clustering

Lower operating

temperature obviates

need for retention

barrier

Cost

Increased core volume and control requirements dictate element size

Reactivity requirement of $\Delta k / k=\$ 32.50$ for SNPS reactor cannot be obtained by reflector contro1
Segmented elements may give rise to local stress concentrations in cladding

Better heat transfer

Fission product contamination of primary system is not critical in SNAP. However, in the SNPS it must be minimized.

The development program should address the hydraulic design of the fuel assembly and the core inlet plenum

In-core control will provide local flux and temperature peaking factors that exceed those experienced in homogeneous core designs. 
Table II (Cont'.d)

COMPARISON BETWEEN SNAP REACTORS AND PROPOSED SUBSEA NUCLEAR POWER SYSTEM

\section{SUBSYSTEM COMPONENT}

- Control mechanisms

- Shield

- Primary loop coolant pump

$\bar{\omega}$

\section{PREVIOUS DESIGN}

Moveable reflector

components

DC E-M pump

AC E-M pump

-rack and pinion

drives operating

from above core

$5 \& 3 / 16$ " borated steel serpentine rock concrete

Necessary to protect vesse1, to provide and access for mainten- and irradiation is ance. unknown; tests required.

The proposed pump has not been built and tested, but it appears to be an extension of wel1-known technology (See Appendix 3).

- Primary loop heat exchanger

- Fuel transfer
NaK - Hg boiler

NA to expendable space reactors
NaK - toluene boiler

Not discussed in the summary report, but described in a letter

to ADL (See Appendix 4)
New coolant

No experience exists

to qualify a $\mathrm{NaK}$ -

toluene boiler as a

20-year system

component.

Prior to operational test at power it will be necessary to show

that a rellable,

serviceable method

exists to remove

irradiated and perhaps damaged fuel elements

and to transfer them to appropriate casks or

storage facilitles.

This must be done con-

currently $\mathrm{w} /$ reactor

develonment. 
SNAP reactors. Such calculations are necessary to determine required coolant flows and satisfactory fuel element performance. Therefore, the reactor core development program will necessarily be significantly more complex and of greater duration than preceding SNAP core development programs. AI's previous experience with rodded core reactors, which include Hallam, the Sodium Reactor Experiment (SRE), Piqua and OMRE, ${ }^{4}$ should ensure that a satisfactory SNPS core design can be developed.

Control rod drive mechanisms were not needed for SNAP reactors, but are another factor to be considered for the SNPS reactors. AI has performed a literature survey of control rod drives, and concluded that standard industrial components for such drives would be acceptable. Although such components could probably be adapted to the proposed SNPS system, an intensive test program would be required to demonstrate that prototypical units can perform satisfactorily. The SNPS development plan provides for such tests.

The proposed shielding concept is not based on SNAP technology, but is a new configuration using known shielding materials. At present, the design calls for a 5 and $3 / 16$ th inch borated steel thermal shield surrounding the core; serpentine concrete is then used in appropriate geometry and thickness to maintain an acceptable neutron flux inside the reactor module. The thermal shield is necessary to limit the temperature of serpentine concrete, which will lose shielding effectiveness due to water loss above $900^{\circ} \mathrm{F}$.

The long-term performance of serpentine concrete under irradiation and high temperature is unknown. AI does plan to conduct short-term thermal tests to determine the stability and thermal conductivity of the concrete after initial thermal bake-out treatments.

Primary coolant (NaK) flow in the proposed SNPS reactor will be maintained by a new pump design, which would be an extension of previous SNAP experience. The proposed design would use ac excitation instead of dc (SNAP pumps) to induce currents in the liquid metal coolant, thereby providing flow with no moving parts in the pump. Pumps using this general concept have been built for other applications, ${ }^{5}$ e.g., pumping molten aluminum, but the particular design proposed for the SNPS reactor has not been tested via a prototype model. This is an area requiring additional input.

The primary loop heat exchanger is a completely new component, unrelated to SNAP technology. It is of critical importance to satisfactory operation of the proposed SNPS reactor. AI has considered at least two variations of the basic design and placement in the primary coolant loop, and design modifications as prototype units are built must be expected. We should point out that the Sundstrand Corporation, which would be responsible for all the rest of the working fluid (toluene) components and systems, has employed other types of boilers in its previous power generating systems. These boilers (heat exchangers) usually employed hot gases as the heat source, so that their experience would be of limited value to AI in designing liquid-metal to toluene heat exchangers. In summary, this primary loop heat exchanger is a critical part of the SNPS system. It has no data base from previous SNAP programs, or from industrial experience. We believe, therefore, that this component will require more design and developmental effort than scheduled.

4. See Appendix 2 for additional detalls on these reactors.

5. See Appendix 3 for a survey of E-M pumps and applications. 
Finally, fuel transfer as part of the refurbishing operation should be considered in more detail. We realize that this particular item, transfer of "hot" and/or damaged fuel, is not of critical importance in the initial phases of developing a prototype reactor, but it is important to plan now for the procedures which will be required to handle spent fuel. Although the summary report does not describe a SNPS refueling and refurbishing station in detail, AI has supplied us with more specific plans for the facility. These plans appear in Appendix 4.

\section{Petroleum Engineering}

As with marine engineering, LPS has a significant amount of experience in petroleum engineering as it applies to subsea completions. Current testing on the Gulf of Mexico cellars and manifold, along with the scheduled 1977 installation of Petrobras cellars and a (larger) manifold should do much toward confirming their ability to construct reliable subsea completion systems. Our comments here, as in the previous section, relate to the summary report and items needing either revision or additional attention.

First, reference is made to production (ultimately) in the 3,000 to 10,000 foot depth range in Section 2.0 of the Summary Report. We emphasize that production at such depths is very much in the future, because the great majority of offshore production will come from wells in 2,000 feet of water or less for the next two decades.

The bulk transfer of crude oil via pumping has been put forth as the main justification for developing a SNPS. However, the pumping station as described in the Summary Report does not exist at present. For the hypothetical field application (see the following section), this pumping station would receive an input of 50,000 barrels of oil per day (BOPD) along with substantial amounts of gas. The amount of gas in vapor form depends on the pipeline pressure, so that twophase flow (gases and liquids) into the pumping station is anticipated.

No pumps exist which can handle two-phase fluids at 50,000 BOPD, and it is unlikely that such a pump can be built due to the nature of the input fluid. ${ }^{6}$ This means that separators (both primary separators and secondary gas scrubbers) would be required, along with gas compressors, fluid pumps, associated control systems and recombination piping. The pumping station, as envisioned by LPS, would include the separation equipment described above, ten centrifugal multistage compressors (suitably manifolded so that remote connection/cutout capability exists), five fluid pumps (similarly manifolded) plus the control systems. After the gas has been compressed, and the fluid repressurized, the two phases would be recombined for transmission to the processing platform or ship.

Pump maintenance is an item of concern to us. The extent or frequency of maintenance depends in large degree on the quality of fluid being pumped. Therefore, if the wells produce a particularly corrosive or abrasive mixture of fluids it is likely that seals and other components would require maintenance on a frequent basis. At this time LPS anticipates that a pumping station would require two service visits each year, of 14 days each.

6. The varying combination of gas and liquid presents an unbalanced load on the impeller; furthermore, gas pockets and "slugs" of liquid would cause very large cyclical pump loadings. 
The foregoing discussion causes us to raise a very basic question concerning the SNPS and its primary function. The question is of compatibility. It does not seem logical to couple a SNPS, whose prime virtue is that it can operate four years without attendance, with a pumping station (which must be located nearby) that requires attention on a fairly regular basis. This combination of qualities would prohibit the use of a SNPS and pumping station under permanent polar ice, for example. The only type of sub-ice arctic application for a SNPS and pumping station would be in the Beaufort Sea or other areas where ice gives way to open water for several months of the year.

\section{The Turbine/Generator System}

Arthur D. Little, Inc. has reviewed the proposed design for a single-stage toluene turbine as put forth by the Sundstrand Corporation, and the specifications of desired generator output. Our discussion of the gearbox and generator will follow this brief summary of turbine analysis.

The stated characteristics of a SNPS turbine, which would use toluene as the working fluid, are as follows.

Turbine type single stage impulse, supersonic

Turbine inlet pressure .500 psia

Turbine inlet temperature $.700^{\circ} \mathrm{F}$

Turbine exhaust pressure 1.75 psia

Turbine exhaust temperature. $.466^{\circ} \mathrm{F}$

Turbine efficiency $80 \%$

Flow rate $34(\mathrm{lb} / \mathrm{sec}$.

Turbine rotational speed $.8000 \mathrm{rpm}$

Turbine blade tip diameter. 34.0 inches

Turbine blade height 5.2 inches

Turbine speed control. upstream throttle.

We estimate, from a check on the thermodynamic performance, that the expected efficiency of $80 \%$ at design conditions is readily attainable. Designs using optimal practice can reach $85 \%$ efficiency. However, because the turbine nozzles operate in the supersonic flow regime (Mach number $=3.3$ at design conditions) and the ratio of specific heats for toluene is so near unity, the turbine efficiency is sensitive to operating conditions. In other words, one can expect a sharp drop-off in efficiency under off-design conditions where shock losses are added to normal inefficiencies.

At $700^{\circ} \mathrm{F}$, we calculate that the maximum blade stress in tension will be well within conservative operating levels. Attention should be directed toward ensuring that dynamic stresses arising from natural vibration modes will not be troublesome.

Insufficient information is available to review other important design considerations such as critical shaft speeds, long-lived bearings, seals and provisions for lubrication. Nevertheless, in all these areas we would judge the demands on design to be relatively moderate compared to gas turbine design problems. Pressure balancing of the turbine disk through seal location and the thrust bearing itself do need special design attention. Furthermore, tests of the full scale unit should be required prior to acceptance for SNPS duty. 
In summary, the simplicity of design proposed for this turbine and its relatively benign operating conditions should present no barrier to developing an appropriate SNPS turbine. Sundstrand's recent contract with ERDA for $600 \mathrm{~kW}$ machines should also improve their design data base for the proposed $3 \mathrm{MW}$ turbines.

AI originally proposed using a direct-coupled $400 \mathrm{~Hz}$ generator to avoid problems associated with a reduction gearbox. Consideration of frequency arose from the fact that a two-pole alternator (the simplest type) driven at $8000 \mathrm{rpm}$ would produce alternating current at $133 \mathrm{~Hz}$, which is a non-standard frequency. A six-pole alternator would produce $400 \mathrm{~Hz}$ ac, which is a standard aircraft power frequency. This, too, would be of little value to conventional oil pumps operating on $60 \mathrm{~Hz}$ current. We suggest that conventional gearboxes can be built to the standards desired (35,000 hours between overhauls), and that conventional $60 \mathrm{~Hz}$ alternators can be adapted successfully. ${ }^{7}$ Our estimates are as follows (1977 dollars):

$3 \mathrm{MW}$ alternator, $60 \mathrm{~Hz}$ $\$ 75,000$

2.22 to 1 reduction gear, $4000 \mathrm{Hp}$,

with pressure lube system $\$ 28,000$

TOTAL

$\$ 103,000^{*}$

The dimensions of this system are roughly 4 feet in width and height, and 7 feet in length; total weight would be about 13 tons.

\section{B. ECONOMIC REVIEW}

\section{Description of Example}

Our attention is now focused on Section 4.0 of the AI/LPS summary report, which defines a typical field application and associated economic data over a 24 year period. Section 4.1 describes the example in general terms; key data are reproduced below.

Location Gulf of Mexico

Water depth 1,200 feet

Production rate. $50,000 \mathrm{BOPD}^{* *}$

$\mathrm{GOR}^{* * *}$ (gas to oil ratio) $.1,000$

Number of wells ...20

Well completions Subsea, dry tree

Distance to the nearest processing platform. .40 miles

Minimum wellhead flowing pressure 1,000 psig

Platform water depth .400 feet

Field life .20 years

It is assumed that a booster pump will be required for the bulk transfer of oil at 50,000 barrels per day from the manifold center outlet to the platform. This pump will be powered by the 3 MW SNPS module.

7. During our visit to Al in late November it became clear that they intended to abandon the $400 \mathrm{~Hz}$ approach also, in favor of $60 \mathrm{~Hz}$ power.

"Cost data from Westinghouse and the Solar Gas Turbine Division of International Harvester.

* $B O P D=$ barrels of oil per day

***GOR = standard cubic feet (SCF) of gas per barrel (42 gallons) of oil 


\section{A General Comment}

It is assumed that this field will produce roughly 310 million barrels of oil over its projected lifetime (20 years). A field this large, which is almost giant-sized ${ }^{8}$, would be extremely unusual in the Gulf of Mexico. Only six fields larger than 300 million barrels have been found in the Gulf, and they were all discovered prior to 1954 . Since the largest fields are the easiest to find, this implies that the probability of discovering another semi-giant field of 300 million barrels is rather low.

\section{Production}

It is implied in the summary report that water injection will be employed to maintain fluid production at a constant rate of 50,000 BOPD from year 4 (when all 20 wells have been completed) to year 24. Although this situation may occur in a real production field, with a combination of fortuitous gas and/or water drive conditions, a more likely production profile would show relatively constant volume in the early years and declining production in the subsequent years until it fell to an uneconomic level. Therefore, while realizing that this is a purely hypothetical example, our first revision in the economic analysis consists of a reduction in production from year 18 onward, to zero production in year 23 . We have chosen an exponential decline, such that volume in each year is proportional to $\mathrm{e}^{- \text {an }}$ where $\mathrm{a}=.5$ and $\mathrm{n}=1$ through 5 . The assumption has also been made that no pumping power is required for water injection. This, too, may be essentially true (certainly some pumping is required for water transfer at the platform) in some cases but not in others. However, since this pumping power requirement could presumably be met from the platform power supplies we will not include these energy costs in the SNPS economic analysis.

\section{Capital Cost Items}

Many assumptions were made in the summary report concerning the cost of various items and procedures. For Item 1, drilling, the cost will be a function of water depth, sea conditions, geographic location and other conditions. ${ }^{9}$ Items 2 (cellar completions) and 3 (flowline bundles) will depend primarily on depth and sea conditions. LPS has asserted that the costs assumed in the summary report for Items 1, 2 and 3 are valid in 1977, for the hypothetical field example, due to improvements in operating procedures or component designs. We have found nothing to challenge this assertion in performing our analysis, and will therefore employ these estimates.

\section{Item or Activity \\ Cost, $1977 \$$}

Item 1. Drilling from ships or semi-submersible rigs

Item 2. Wellhead cellar completions

Item 3. Flowline bundles (installed)

Item 4. Platform modifications

\author{
$\$ 4,000,000 /$ well \\ $\$ 800,000 /$ well \\ $\$ 600,000 /$ well \\ $\$ 10,000,000$
}

8. A giant oil field is one containing more than 500 million barrels of estimated recoverable oil.

9. For example, the complexity of the drilling program, the drilling equipment used, weather conditions, well depth and proximity to support services. 
Item 4 is definitely not a "hard" number, but one which could assume a range of values. For example, if the subsea-completed wells were drilled near a platform which previously served a high production capacity field whose production had now declined substantially, then relatively little cost might be required to add processing capacity. Conversely, if the wells were drilled near a platform whose processing equipment was completely utilized, the cost of adding extra capacity might be $\$ 20$ million or more.

LPS, which would build the proposed manifold center capable of handling 20 wells, has suggested that a revised cost estimate of $\$ 14$ million would be more appropriate than the original $\$ 10$ million estimate; we concur.

\section{Item 5. Manifold center for 20 wells}

\section{$\$ 14$ million}

Pipe laying is a major cost item in developing the field. In the example, it was assumed that both a 16 inch diameter crude oil transfer pipe and a 10 inch water injection line could be laid simultaneously, at a rough cost of $\$ 1,000,000$ per mile over a 40 -mile distance. Our estimate ${ }^{10}$ for placing two such pipelines in "average" Gulf of Mexico sea conditions are roughly $\$ 15$ million for the 10 inch line, and $\$ 25$ million for the 16 inch crude handling pipeline. Thus our total is compatible with the original $\$ 40$ million estimate.

\section{Item 6. 40 miles of $10 \mathrm{inch}$ and}

$\$ 40$ million 16 inch pipe, installed

The pumping station has been described in Section II.A.3. It would consist of a large number of remotely-controlled compressors and pumps, including spares also under remote control. The point should be emphasized again that no such pumping station exists at present. Regarding cost, a balance must be struck between the number of pumps desired for reliability and the size of the enclosure. We believe the original $\$ 12$ million estimate is probably too low, and would suggest an estimate of $\$ 14$ million for the cost of a pumping station.

\section{Item 7. Complete pumping station}

\section{$\$ 14$ million}

The next cost item of significance is the seafloor nuclear power supply itself. AI, in a meeting at their headquarters, stated that the 1974 estimate of $\$ 8,400,000$ (installed) was still a reasonable figure. Frankly, we have grave doubts that a new nuclear reactor, sodium to toluene heat exchanger, toluene turbine and other novel components can be produced at this cost on a regular basis.

Historically, the cost estimates for advanced technological systems which have been developed by the proponents of such systems have almost without exception been lower than actual costs. As with any new venture, it is impossible to predict the problems one may encounter and the cost of satisfactory solutions. Relative to this point, AI has stated that no direct experience exists for constructing $\mathrm{NaK}$-toluene boilers. They plan to follow a semi-empirical approach to boiler design, development and testing. Estimating the cost of such an approach simply can not be done precisely.

10. These estimates are based on articles in the Oil and Gas Journal issues of August 23, 1977 and August 2, 1974. 
Although we are discussing a small nuclear power supply, the ten-fold cost escalation of large central-station nuclear power plants bears mention. Much of that increase is due to high interest rates and long construction times. Nevertheless, part of the increase is due to escalating materials and labor cost. There is no reason to suspect that these items will decline in cost during the next decade or so; rather, it is generally assumed that prices for these items will follow the general trend of inflation.

As part of our review, we compared the development program cost estimates proposed by AI in their document ER-652-120-001, and previous AEC programs. For example, in the first six years of the SNAP-2 program, AEC program costs were $\$ 64$ million or slightly more than $\$ 10$ million per year. In the total SNAP-2 program (11 years), AEC costs were $\$ 92$ million or approximately $\$ 9$ million per year. For the SNAP-8 program, annual costs were roughly $\$ 7$ million over a period of nine years.

In 1974, AI estimated that it could develop and build the reactor and power system in five years at a cost of $\$ 27.5$ million (exclusive of marine hardware and testing).

With previous reactor experience limited to thermal power of $1 \mathrm{MW}$ or less, and organic Rankine cycle combined rotating units (CRU's) limited to $100 \mathrm{kWe}$ or less, it is difficult to see how the reactor size can be scaled by a factor of 10 , and CRU's by a factor of 30 in five years at an annual cost roughly one-third that of the combined SNAP-2 and SNAP-8 programs. This projection is made with no allowance for inflation between the mid-60's and 1974. Inflation alone would make the ratio of annual SNPS costs to annual combined SNAP costs about 1:5.

As unbiased reviewers of the SNPS concept, one of our tasks is to examine cost estimates and determine, to the best of our ability, whether such estimates are excessive, unrealistically low or reasonable. We have concluded that actual costs for the nuclear power station, pressure vessel, et al. will quite probably be higher than the estimates supplied by AI. The extent of increase, in more quantitative terms, however, is subject to debate due to the hypothetical nature of a SNPS. Based on AI's preliminary production planning for the SNPS, we suggest a minimum cost premium of $20 \%$ over the AI basic cost estimate. This $20 \%$ premium should be considered as a lower bound on the cost of a commercialized SNPS. Due to a lack of detailed production plans, we can not present a justifiable upper bound on cost.

AI's estimates in the summary report were as follows (1974 dollars):

Item A. Nuclear Power System Components

Item B. Pressure Vessel Enclosures, et al.

AI total for Items A \& B:

ADL cost premium multiplier:

ADL estimate for Items A \& B (1974 dollars):
$\$ 3.7$ million

$\$ 1.9$ million

$\$ 5.6$ million

$\mathrm{x} 1.2$

$\$ 6.7$ million

The barge/base (Item C) completes the SNPS. Lockheed Petroleum Service has estimated that this item would cost $\$ 2.13$ million. Although the technology required to construct the barge/base as currently designed is significantly less demanding than that of the reactor system, it should be emphasized that no such "vessel" has been built yet. Therefore, we believe it is prudent to add at least a $5 \%$ contingency factor to the LPS estimate. 
Item C. Barge/base (LPS estimate)

plus $5 \%$ contingency allowance

ADL estimate for Item C:
$\$ 2.1$ million

.1

$\$ 2.2$ million

Prior to considering inflation, our estimate for the total capital cost (less installation) of an SNPS is the total of Items A, B and C.
ADL estimate for complete SNPS
$\$ 9.0$ million

(1974 dollars):

Inflation, as measured by the decline in purchasing power of consumer goods, will increase most of the 1974 cost estimates of the summary report. From current published data, ${ }^{11}$ prices as of January 1, 1977 were $118 \%$ of 1974 prices. Rather than speculate on what the exact multiplier should be for April of 1977, we will simply use 1.18 as the correction factor for 1974 prices and acknowledge that it may underestimate current prices slightly. Our revision of SNPS costs is as follows.

\section{ADL ESTIMATES}

\section{Data}

Items $\mathrm{A}, \mathrm{B}$ and $\mathrm{C}$ :

Item D. Installation Cost:

Item E. Total SNPS Cost:
AI has assumed that one "spare" SNPS should be available for every four placed in operation, which appears reasonable to us. The adjusted capital cost for an SNPS unit would be $125 \%$ of Item $\mathrm{E}$, or 14.2 million in 1977 . This is the figure we will use in our economic analysis as the capital cost of a seafloor power supply.

Item 8. Total adjusted capital cost

$\$ 9.0$ million

$\$ .64$ million

$\$ 9.6$ million $\times 1.18$
1977 Data

11.3 million of SNPS

\section{Expense Items}

In the early years of field production, depreciation of the capital costs will be the major annual expense. This is particularly true for accelerated depreciation, which we will describe and use in a following subsection.

The largest expense item after depreciation is platform operating cost. The summary report established a range of $\$ .30$ to $\$ .60$ per barrel of oil produced, and selected $\$ .40$ per barrel as a reasonable figure for the sample calculation. We see no reason to adjust this particular assumption. At 50,000 BOPD this cost is $\$ 7.3$ million per year. We have reduced operating expenses in years $18-22$, reflecting the decline in production. ${ }^{12}$

11. Data taken from the February Survey of Current Business, a Department of Commerce Publication, Table S-9. 1967 is the base year $(\$ 1.00) ; 1974$ shows purchasing power of $\$ .678$, compared to $\$ .574$ for January 1,1977 . The price multiplier is $.678 / .574=1.181$.

12. It is conceivable that operating expenses per barrel will be more in the final years, but how much more is a function of well conditions. 
Insurance costs were estimated to total $\$ 4$ million per year, based on $3 \%$ of installed value for subsea facilities and $10 \%$ for platform additions. It is probable that the developers will have to carry additional liability insurance, as operators of a potentially hazardous unattended subsea nuclear power supply. Naturally, one can only make very tentative estimates of what such liability insurance might cost for an SNPS in a remote location. As a starting point, we would suggest an annual figure of $\$ 100,000$, corresponding to $\$ 40$ million of liability coverage. This is comparable to present-day civilian nuclear power plant rates. The annual insurance expense, based on the revised capital cost estimates, is shown below; coverage starts in year 3 and is dropped in year 22 .

Subsea assets: $\$ 134 \times .03=\$ 4.1$ million per year

Surface assets: $\$ 10 \times .10=\$ 1.0$ million per year

Additional liability: $\$ 100,000=\$ .1$ million per year

\section{Item 10. Insurance expense}

$\$ 5.2$ million/year

Periodic maintenance of all subsea facilities by the LPS service vessel and capsule is anticipated. The actual cost is likely to lie within a broad range, since the critical component of this cost is the quality of oil produced. Wells producing especially high-quality, contaminant-free crude may require maintenance only every two or three years. Conversely, crude accompanied by large quantities of wax, brine, sand, $\mathrm{H}_{2} \mathrm{~S}$ or other problem materials may cause wells to need maintenance several times per year. In the sample calculation, a level of maintenance corresponding to $\$ 50,000$ per well per year is assumed. A more recent estimate by LPS suggests that a figure of $\$ 100,000$ would be appropriate today. Using this figure, maintenance for 20 wells would cost $\$ 2$ million per year.

\section{Item 11. Maintenance of subsea facilities}

$\$ 2$ million

In the summary report, fuel and refurbishment of SNPS units on a regular basis were estimated to cost $\$ 534,000$ per year, over a 20 year period, at a $12 \%$ discount rate. This corresponds to a cost of $\$ 2.7$ million incurred every four years, after production starts. This cost estimate, like that for the SNPS itself, is based on proposed designs and procedures. Prototype hardware and tested procedures do not exist. Refurbishing cost also depends on future fuel cost (a difficult item in itself), the size and thus the cost of the refueling/refurbishing facility, as well as procedures which will be employed. Al's 1974 estimate, updated to 1977 costs, and escalated by $20 \%$ as a risk premium for this particular new technology, results in a refueling/refurbishing cost estimate of $\$ 3.35$ million in years $4,8,12$ and 16 following full production. AI also assumes a periodic change-out every four years at $\$ 1.12$ million. This, adjusted for inflation, is $\$ 1.32$ million. The Arthur D. Little estimate for SNPS maintenance is the total of these two figures (refuel and refurbish plus change-out operations), or $\$ 4.67$ million every four years after startup.

Item 12. SNPS maintenance, in years

$\$ 4.67$ million

\section{$4,8,12$ and 16 following startup.}

(NOTE: these expenditures equal $\$ .92$ million per year at a discount rate of $10 \%$ ) 


\section{Oil Pricing and Revenues}

An historical survey of oil prices in the U.S. is complicated by the federal government's decisions in recent years. A key concept, that of distinguishing between "old" oil and "new" oil, was contained in the Emergency Petroleum Allocation Act (EPAA) of December, 1973. Old oil was defined as oil produced ${ }^{18}$ from fields developed prior to this date. A ceiling price was placed on old oil, based on prices as of mid-May, 1973, such that $\$ 5.25$ was the upper limit of old oil price during the period from December, 1973, to December, 1975, when the EPAA expired. During this period, new oil was free to rise in price until parity with imported oil was achieved.

The Energy Policy and Conservation Act became effective in February, 1976. Under this act, the FEA was directed to establish crude oil pricing policy which included the concept of a weighted average national oil price. For the year 1976, the weighted average of old oil (or lowertier oil) and new oil (upper-tier oil) was specified to be $\$ 7.66$ per barrel. In succeeding years, this average price may increase at a maximum rate of $10 \%$ per year. Thus it is clear that both old and new oil prices are now under governmental control.

With the preceding discussion in mind, we turn now to examine Figure 1. This graph shows the historical price (so-called "current dollars") in dollars per barrel of oil produced off the coasts of Louisiana and Texas during the years 1966-1975. The unit production value is the total of average marketed value of old and new oil less allowances for transportation. ${ }^{14}$ It is not possible to split out new oil from old oil in determining production values. Transportation will be discussed after a few additional comments on the graph.

Royalties and rental fees are payments to governmental units which are made by the oil companies when oil is being produced in outer continental shelf (OCS) areas; there are no severance taxes. Royalties are calculated as a percentage (usually $16-2 / 3 \%$ ) of the value of the oil with an allowance being made for product processing costs. Rental fees are usually about $\$ 3$ per acre per year and the unit value shown here is simply total rentals divided by total annual production. It is clear from the graph that royalty payments dominate rental and bonus payments in this time period.

The bonus values per barrel as shown here are hypothetical values. There is no simple and direct method by which bonus payments can be linked to oil production since production begins (if it ever does) 4 to 6 years after payment of the bonus and may continue for 20 years or more. For the Gulf of Mexico we can use 20,000 barrels per acre as an estimate of the average yield per producing area for existing fields. To obtain a bonus cost in dollars per barrel, we divided bonus payments by the amount of acreage involved times 20,000 barrels per acre. Since this involves a flat estimate of recoverable reserves, the resulting cost has not been lagged to reflect the actual delay between bonus payment and the start-up of production. Of course, many bonus payments are applied to tracts which result in no crude oil production.

13. Volume was also considered; If a developer raised production beyond a specified previous rate, the excess over that rate was treated as new oll for pricing purposes.

14. The data source is "Outer Continental Shelf Statistics," June 1976, U.S.G.S., Department of the Interior. 


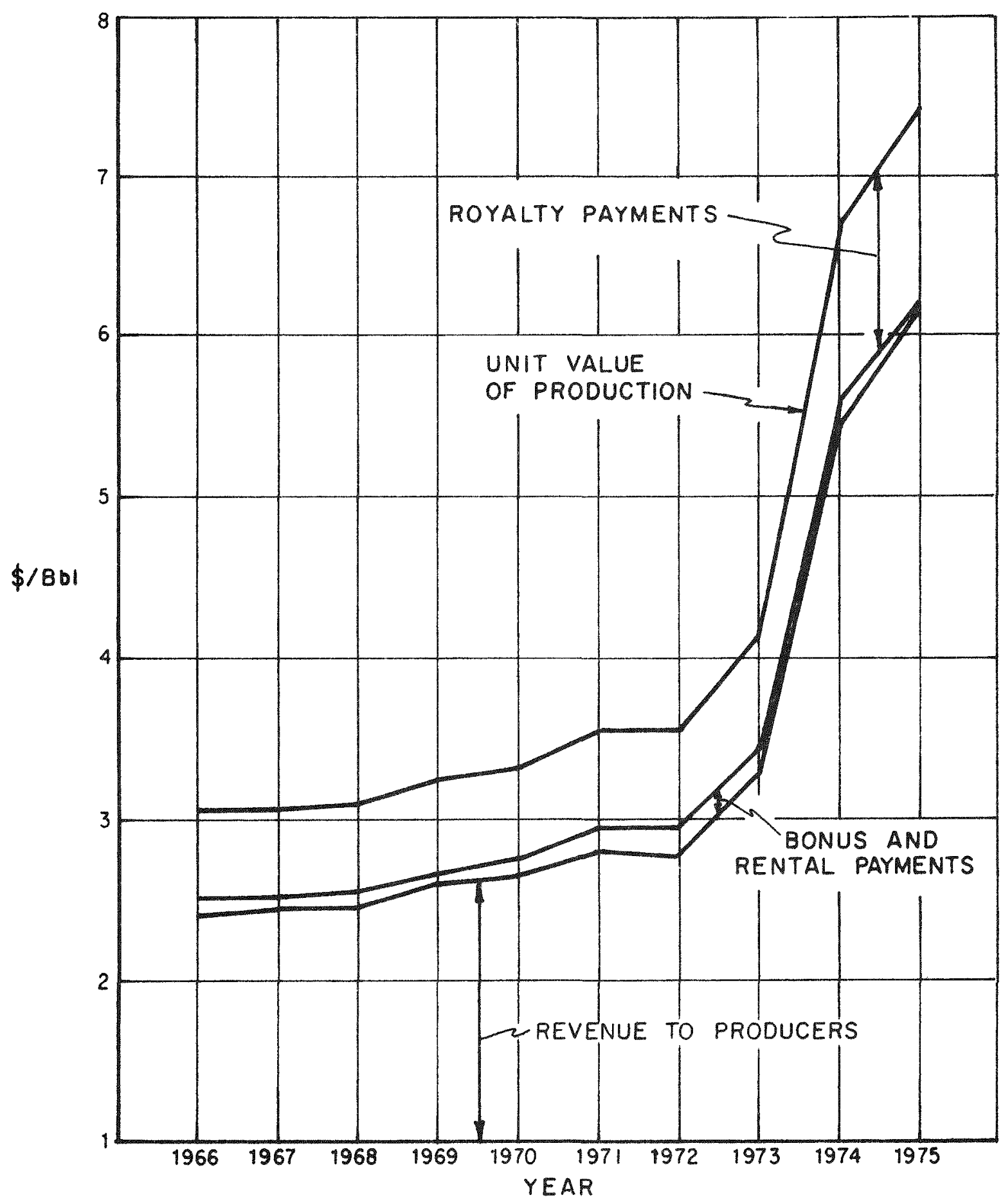

FIGURE 1 UNIT RESIDUAL VALUE OF GULF COAST OIL PRODUCTION 
It must be emphasized strongly that the preceding discussion of bonus payments applies to historical data. At this time, and for the foreseeable future, federal policy relevant to bonus payments on leasing areas will result in substantially larger payments. On a per-barrel basis, the size of the bonus payment will be different for every leasing area. We can only state that developers are currently considering bonus payments in the range of $\$ 1-2$ per barrel. Thus for any future OCS field development schemes, bonus payments must be considered as a potentially significant economic factor.

Another cost item which has not been discussed so far is the expense associated with finding oil fields. This, too, is highly field dependent. To put this cost in perspective, however, a figure on the order of $\$ .50$ per barrel is a reasonable estimate.

The cost of transporting oil from the field to a refinery is not of major concern for Gulf Coast oil fields, being in the neighborhood of $\$ .25$ per barrel. However, transportation costs for delivering North Slope through the Trans-Alaskan Pipeline System (TAPS) and then by tanker can be from $\$ 5.00$ per barrel (West Coast refineries) to $\$ 8.00$ per barrel (Gulf Coast refineries). ${ }^{15}$

Under these conditions, if an Alaskan field developer had to compete with crude at $\$ 13 / \mathrm{bar}$ rel delivered to the lower West Coast, his wellhead price would have to be about $\$ 8.00$ per barrel. If we lump royalty payments and rentals together at roughly $18 \%$ of the wellhead price, the revenue from the field would be roughly $\$ 6.50$ per barrel to the developer (less bonus payments).

From the preceding comments, it may be evident that fields developed in the Gulf of Mexico will enjoy a significant advantage in terms of revenue to the developer compared to Alaskan fields. If imported crude were priced at $\$ 12 /$ barrel on the Gulf Coast, pre-bonus revenue to a Gulf field developer could be roughly $\$ 8.50 / \mathrm{barrel}$. This calculation assumes transportation cost of $\$ 1 /$ barrel (which is a high estimate), a wellhead price of $\$ 12 /$ barrel and royalties plus rentals of $\$ 2.50 /$ barrel.

Based on the foregoing discussion, we will assume a pre-bonus revenue to the developer of $\$ 8.50$ per barrel (1977 dollars) for the hypothetical Gulf of Mexico field described in the summary report.

\section{Economic Analysis}

Our analysis will be similar in principle to that of the summary report, which used discounted cash flows to arrive at an internal rate of return for the oil field developer. However, where they used $12 \%$ as the discount rate (reflecting the money market conditions of 1974), we intend to use $10 \%$. This choice is typical of the minimum "rule of thumb" rate which corresponds to 3 percentage points above the current prime rate $(7 \%)$. We will also assume a $50 \%$ corporate tax rate, double-declining-balance depreciation and the year-end cash flow convention. All capital cost items $(1-8)$ are assumed to have a 20 -year life, and well costs are split $30 \% / 70 \%$ between capital costs and expense.

15. See the article "What Price for Alaskan Oil" by W.A. Bachman in the March 14, 1977, issue of the Oil and Gas Journal for additional comment on this topic. 
The goal of this analysis is to determine the after-tax internal rate of return (IRR). All costs will be expressed in 1977 dollars. In recognition of the fact that a SNPS would probably not be employed earlier than 1987, we have prepared a table showing what 1987 costs and revenues would be on the basis of $7 \%$ inflation (on average) per year for this decade. The internal rate of return will be the same, of course.

Cash flows occurring during the life of the example are shown in Figure 2. The large investments required in years 1 through 4 are clearly evident, as is the decline in annual revenue during the final years when production is decreasing. The income statement for each year is derived from the cash flows occurring in that year. Table III shows the income statement for years 3 through 22 . For any given year, the revenue is equal to $\$ 8.50$ per barrel times the annual oil production. E.B.T. for each year is earnings before (income) taxes. This figure is simply net revenue minus depreciation and other expenses.

As stated earlier, all of these calculations are done on a pre-bonus basis. The variability of bonus payment size precludes factoring this item into the calculation, but we will comment on its effect after the analysis has been discussed.

\section{Present Worth Analysis}

From Table III, we know the anticipated net income for years 3 through 22 . Using the $10 \%$ discount rate discussed previously, it is a simple matter to calculate the "present" worth of these future cash flows. We have chosen to use year 3 as the base year in these calculations for several reasons. The foremost is that using year 1 would require additional complicating assumptions for the treatment of capital expenditures, and interest in years 2,3 and 4. Second, revenues do not begin to flow until year 3. Furthermore, all investments have not been made until year 4 . The income statement for year 3 does reflect the fact that not all investments have been made at that time; we have accomplished this by revising the depreciation figure accordingly.

The criterion for making an investment decision using the present worth technique of analysis is simply that the present value of all future income must be equal to or greater than the total capital investment. Applying the standard interest formulas, with a discount rate of $10 \%$, the result is quite favorable for the example. A present value of $\$ 535$ million from future income overwhelms the capital cost of $\$ 200$ million. Thus the example meets a basic test of profitability. In order to get a different perspective on its desirability as an investment, we shall calculate the internal rate of return as described below.

\section{Internal Rate of Return Analysis}

The internal rate of return (IRR) is defined as the interest rate which equates the present value of all future cash flows to the initial capital investment. A key point behind using this approach is that all cash flows are presumed to be reinvested at this same (internal) rate of return. Whether or not the annual cash flows can in fact be reinvested at the IRR is a question of great importance, particularly at high rates (IRR $\geq 20 \%$ ).

In the example currently under discussion, the internal rate of return is approximately $39 \%$ without any consideration of bonus payments and finding costs. However, the prime purpose of the federal bonus bidding procedure is to ensure that an appropriate "economic rent" will be received in each lease area. In practice, this means bonus payments would (theoretically) be sufficiently large so that the net after-tax return to the developer would be on the order of $15-20 \%$. 


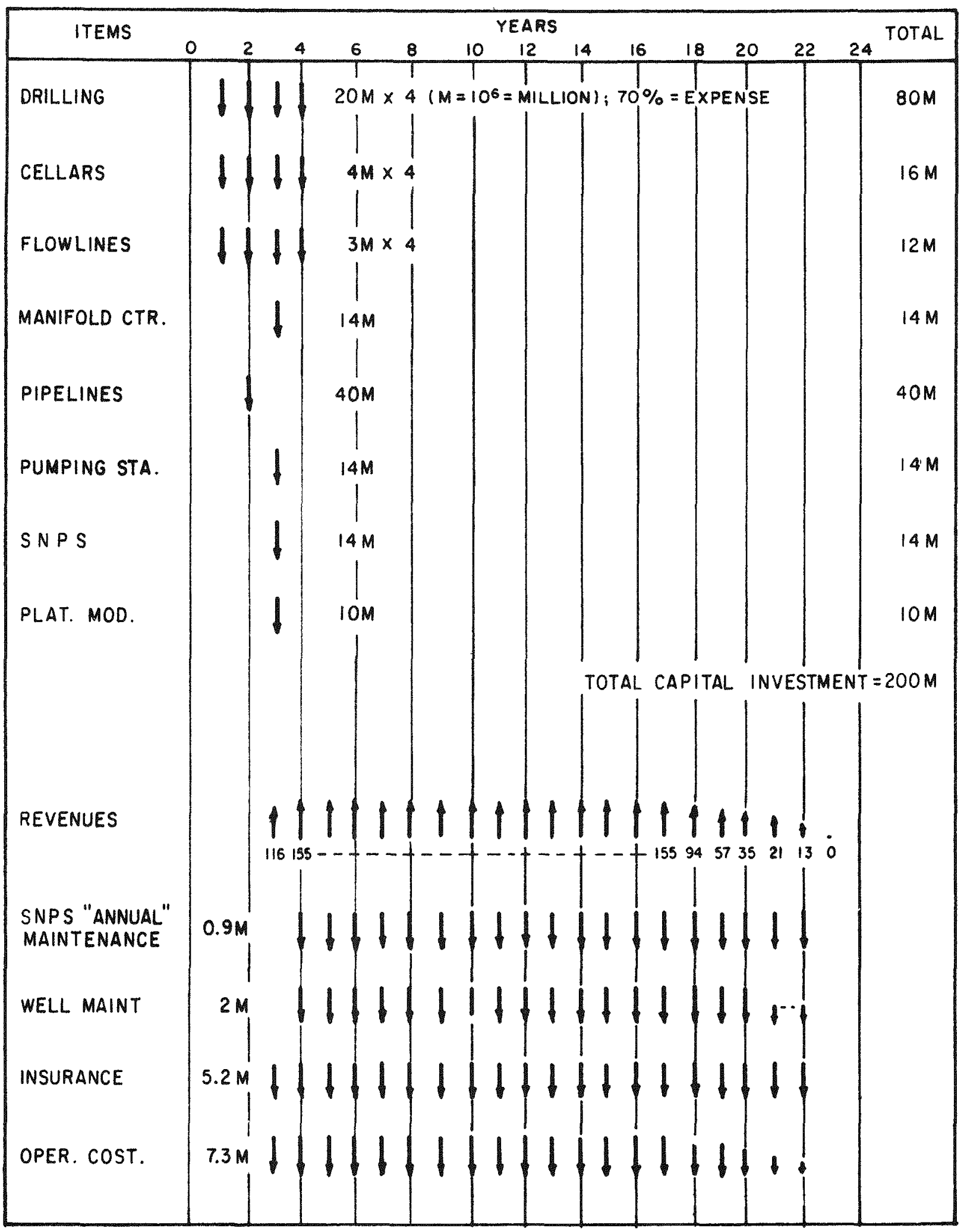

FIGURE 2 CASH FLOWS - ADL, INC. ESTIMATES 
ALL ITEMS IN MILLIONS OF DOLLARS

\begin{tabular}{|c|c|c|c|c|c|}
\hline YEAR & 3 & 4 & 5 & 6 & 7 \\
\hline Revenue & 116.3 & 155.1 & 155.1 & 155.1 & 155.1 \\
\hline Depreciation & 8.5 & 14.4 & 13.0 & 11.7 & 10.5 \\
\hline Expenses & 25.6 & 29.4 & 15.4 & 15.4 & 15.4 \\
\hline E.B.T. & 82.2 & 111.3 & 126.7 & 128.0 & 129.2 \\
\hline $\mathrm{IT} / \mathrm{NI}$ & 41.1 & 55.7 & 63.4 & 64.0 & 64.6 \\
\hline $\mathrm{PWF}$ & 1.0 & .91 & .83 & .75 & .68 \\
\hline $\mathrm{PW}_{3}$ & 41.1 & 50.6 & 52.6 & 48.0 & 43.9 \\
\hline YEAR & 8 & 9 & 10 & 11 & 12 \\
\hline Revenue & 155.1 & 155.1 & 155.1 & 155.1 & 155.1 \\
\hline Depreciation & 9.4 & 8.5 & 7.7 & 6.9 & 6.2 \\
\hline Expenses & 15.4 & 15.4 & 15.4 & 15.4 & 15.4 \\
\hline E.B.T. & 130.3 & 131.2 & 132.0 & 132.8 & 135.5 \\
\hline $\mathrm{IT} / \mathrm{NI}$ & 65.2 & 65.6 & 66.0 & 66.4 & 66.8 \\
\hline PWF & .62 & .56 & .51 & .47 & .42 \\
\hline $\mathrm{PW}_{3}$ & 40.4 & 36.7 & 33.7 & 31.2 & 28.0 \\
\hline YEAR & 13 & 14 & 15 & 16 & 17 \\
\hline Revenue & 155.1 & 155.1 & 155.1 & 155.1 & 155.1 \\
\hline Deprectation & 5.6 & 5.0 & 4.5 & 4.1 & 3.7 \\
\hline Expenses & 15.4 & 15.4 & 15.4 & 15.4 & 15.4 \\
\hline E.B.T. & 134.1 & 134.7 & 135.2 & 135.6 & 136.0 \\
\hline $\mathrm{IT} / \mathrm{NI}$ & 67.1 & 67.4 & 67.6 & 67.8 & 68.0 \\
\hline $\mathrm{PWF}$ & .39 & .35 & .32 & .29 & .26 \\
\hline $\mathrm{PW}_{3}$ & 26.2 & 23.6 & 21.6 & 19.7 & 17.7 \\
\hline
\end{tabular}

NOTES:

1. Earnings before taxes $=$ E.B.T.

2. At $50 \%$ taxation, income tax (IT) $=$ net income (NI).

3. PWF is the present worth factor.

4. $\mathrm{PWF}_{3}$ is the value in year 3 of that particular cash flow. 
Table III (Cont'd.)

Page 2 of 2

INCOME STATEMENTS - ADL ESTIMATES

ALL ITEMS IN MILLIONS OF DOLLARS

\begin{tabular}{|c|c|c|c|c|c|}
\hline $\mathrm{YEAR}$ & 18 & 19 & 20 & 21 & 22 \\
\hline Revenue & 94.1 & 56.8 & 34.6 & 21.0 & 12.7 \\
\hline Depreciation & 3.3 & 3.0 & 2.7 & 2.4 & 2.2 \\
\hline Expenses & 9.4 & 5.7 & 3.4 & 2.2 & 1.3 \\
\hline E.B.T. & 81.4 & 48.1 & 28.5 & 16.4 & 9.2 \\
\hline $\mathrm{IT} / \mathrm{NI}$ & 40.7 & 24.1 & 14.3 & 8.2 & 4.6 \\
\hline PWF & .24 & .22 & .20 & .18 & .16 \\
\hline $\mathrm{PW}_{3}$ & 9.8 & 5.3 & 2.9 & 1.5 & .7 \\
\hline
\end{tabular}

The present worth of future income, using Year 3 as the reference point, is $\$ 535$ million dollars. 


\section{AI/LPS Economic Analysis Versus ADL Analysis}

The total capital investment envisioned by LPS (who performed the original economic analysis) was $\$ 191$ million in 1974 dollars. ADL has estimated a figure of $\$ 200$ million in 1977 dollars would be required to develop the field. The slight difference is due primarily to the fact that $\$ 108$ million of the original estimate, corresponding to drilling, cellars and flowlines, has remained constant. Other capital costs have been adjusted upward by ADL as described previously.

The IRR figure of $48 \%$ quoted by LPS equates $\$ 91$ million per year for 20 years with the initial investment of 191 million. Reiterating, the following points have been made concerning the two analyses.

$\begin{array}{lcl}\text { 1. Capital Cost } & \$ 191 \mathrm{M} & \text { Higher }-\$ 200 \mathrm{M} \\ \text { 2. Operating Costs } & 13 & \text { Higher }-15.4 \\ \text { 3. Production } & \text { Base } & \text { Lower } \\ \text { 4. Discount Rate } & 12 \% & \text { Lower }-10 \% \\ \text { 5. IRR } & 48 \%^{*} & 39 \% \text { (post tax) }\end{array}$

\section{Summary}

It should be reemphasized that the oil field assumed in the hypothetical example is much larger than an "average" Gulf of Mexico field. This is the primary reason that the pre-bonus financial analysis was favorable, despite the cost of a SNPS unit. As stated earlier, the size of bonus payments would presumably drive the internal rate of return down to a traditional level.

The dominant cost factors in determining the potential profitability of an oil field are the drilling costs, completion hardware (cellars, manifolds, flowlines, et al.), and production equipment. Potential revenue in terms of dollars per barrel is still the overriding variable in any economic analysis.

\section{Extrapolation to 1987}

We have shown that the hypothetical example would be a profitable investment at this time, based on anticipated costs and revenues.

Since the economic analysis was done in constant (1977) dollars, its desirability as an investment in the future would remain unchanged as long as future costs and revenues associated with field development rose at similar rates. We would expect that oil prices and field development costs would rise at similar rates, even if the majority of other items used in calculating inflation indices rose at significantly different rates. As an example, suppose in 1982 oil prices took an unexpectedly sharp rise. This would presumably lead to plans for more field development, and greater demand for drilling rigs, platforms, etc. Such demand would very likely drive up the cost of all these items until a "balance" existed similar to the balance before the oil price rise. This type of escalation took place in the North Sea after the oil embargo of 1973.

"Conflicting data in the AI/LPS analysis leave doubt as to whether this figure is a pre-tax or post-tax rate of return. 
For the purpose of illustration, we can present a table of future costs and revenues based on an assumed rate of inflation in the next decade. Forecasting the rate of inflation with accuracy is a difficult task, at best, of course, and one which would require significantly more effort than is warranted for this study. Therefore, we will simply choose a nominal figure of $7 \%$ per annum to indicate the general order of magnitude of future oil price and field development costs.

\title{
1987 REVENUES AND COSTS \\ (1987 dollars)
}

Oil price: $\$ 24$ per barrel, of which $\$ 4.30$ goes to the federal government as royalties, $\$ .70$ represents rental payments, and $\$ 2.00$ is consumed in transportation cost; this leaves $\$ 17.00$ to the developer before taxes. No provision is made for bonus payments.

\author{
A. Initial Development Costs \\ Drilling costs: \\ Wellhead cellars: \\ Flowline bundles: \\ Manifold center: \\ 40-mile pipelines: \\ Pumping station: \\ SNPS: \\ Platform modifications:
}

$\$ 157$ million, of which $\$ 110$ million is expense

$\$ 31.5$ million

$\$ 23.6$ million

$\$ 27.5$ million

$\$ 78.7$ million

$\$ 27.5$ million

$\$ 27.9$ million

$\$ 19.7$ million

\section{B. Annual Revenues and Expense under Production}

Annual revenue:

$\$ 310$ million

SNPS "annual" maintenance:

$\$ 1.8$ million

Well maintenance:

$\$ 3.9$ million

Insurance:

$\$ 10.2$ million

Operating costs:

$\$ 14.4$ million 
BLANK 


\section{OFFSHORE OIL PRODUCTION}

\section{A. CURRENT PRACTICE}

\section{General Comments}

In our discussions with oil company personnel, we encountered a number of generalizations concerning offshore oil production (including arctic areas). The following are relevant to the SNPS.

The first comment is that, historically, use of technology has followed an evolutionary rather than a revolutionary trend. Taking platforms as an example, the trend for jacket types as deeper waters were encountered was essentially an extrapolation of earlier designs. Even for advanced concepts, such as the guyed ("compliant") tower being developed by Exxon, testing of scale models is considered necessary before a firm would employ full-size prototypes in production.

Considering deepwater (depths greater than 600 feet) field development, the consensus is that front-end costs are so high that only "large" fields can be profitably developed. The definition of "large" hinges upon local conditions, of course, and the expected revenue per barrel. For example, a field capable of 50,000 BOPD in the Gulf at a depth of 600 feet and permitting development via conventional (central platform) methods costing $\$ \mathrm{X}$ million might be profitable at a wellhead price of $\$ Y$ /barrel. A North Sea field of 50,000 BOPD might not be profitable at $\$ Y /$ barrel since its development costs would very likely be greater than $\$ \mathrm{X}$ million. If oil prices should rise at a greater rate over time than field development costs, which, realistically, is unlikely, the minimum required size of a field would decrease.

When asked to consider the choice of arctic offshore areas and ice-free areas, production personnel invariably prefer to develop ice-free fields (other factors such as potential profit being equal, of course). This is hardly surprising, but the point is that $48 \%$ of U.S. offshore areas ${ }^{1}$ can be developed by conventional methods or advanced methods now under test. One can assume the oil companies will develop fields by conventional methods as long as they are available and profitable, and turn to arctic areas when little choice exists elsewhere.

With regard to the management of major oil companies, we have observed an unusual mode of operation in several firms. It appears that the exploration division operates rather independently of the production division, such that if a large oil field were to be discovered in certain arctic areas there would be no way to get it developed and marketed quickly. In our opinion, this is because the production division is usually fully occupied with present and near-term field problems. Since production and transportation systems for northern arctic areas have not been developed, it is likely that these areas will be among the last to be developed.

1. The U.S. continental margin totals 890 million acres; of this area, $48 \%$ (427 million acres) is free of ice-related constraints. 
Finally, downhole pumping has been cited as one possibility for SNPS applications. Our information from oil company personnel, however, is that an offshore field without enough natural pressure ("drive") to get the oil to a processing site would probably not be developed. If circumstances dictated, gas lift might be employed; submersible pumps in the wells would not be considered, in general.

\section{Fluid Transfer}

As stated earlier, the SNPS would be used primarily to power a pumping station located on the sea floor. Production fluids (crude oil, gas, brine and other possible fluids) from the wells were to be transported 40 miles at a rate of 50,000 BOPD for the crude and at an unknown rate for gas, water, etc. We have described the problems associated with two-phase fluid pumping in the previous chapter, but wish to discuss some general aspects of pumping and pipelines here.

Separation of liquids from the well output, which consists of a gas-liquid mixture, is necessary before any pumping and transport can take place. Oil company personnel state in general that separation is always cheaper to perform on the surface than on the sea floor. This is one incentive to build advanced platforms in deep water, such as tension-leg platforms or guyed towers. In depths greater than 2,000 feet, subsea separation might be the only option. Exxon has been developing such equipment for its subsea production system, which employs wells drilled through a template on the sea floor as opposed to distributed satellite wells.

Following separation, the gas may be compressed for transmission (usually in a separate pipeline) and the single-phase liquids may be pumped readily through the crude oil line. Gas compression requires significantly more energy than liquid transfer; in addition, the physical size of compressors and drive motors require more space within the pumping station than the highvolume liquid transfer pumps and motors. Thus a low $\mathrm{GOR}^{2}$ would permit a relatively compact separation/pumping station, but a high GOR would probably require a larger and more expensive station.

If a single pipeline is to be employed for pumping both gas and oil, as suggested by LPS, then multiple separation/pumping stations would be required for lines longer than the 40 -mile length of the example. This is because the gas would come out of solution as pipeline pressure drops with increasing distance from the pump, resulting in two-phase flow once again after a certain distance.

\section{B. GEOGRAPHICAL AREAS OF INTEREST WITHIN THE UNITED STATES}

\section{Introduction}

The purpose of this Section is to provide a brief review of the four major U.S. offshore areas where a SNPS could conceivably be employed. Our comments are based on discussions with geologists from the U.S. Geological Survey, interviews with oil company personnel, and a review of pertinent literature. ${ }^{3}$ These comments are not presented as definitive summaries of the petroleum potential for each region, but as additional background on the present assessment of each area with regard to potential SNPS applications.

2. GOR is the gas-to-oll ratio as defined earlier.

3. See Appendix 1 for a list of all references. 
A second factor is that the geology of this area is relatively simple, with the emphasis on "relatively." Compiling and analyzing geological data to determine petroleum potential is still an extremely demanding task for any area. However, the "salt dome" geology commonly encountered in the Gulf is a preferred type. Low fault (earthquake) activity in the area also eases the task of field development.

Third, these two Gulf states are in a favored position for two important aspects of petroleum production. They are a convenient source for labor and materials in developing an oil field. This convenience also extends to processing field output, since, as noted earlier, many oil companies chose to locate refineries there.

If we consider both the 200 mile limit of U.S. control in coastal waters and a 3000 foot depth limitation for field development in the next two decades, the two constraints mesh fairly well in the Gulf. The 1000 meter ( $3280 \mathrm{ft}$.) isobath is always within 200 miles of the coasts of Texas, Louisiana, Mississippi and Alabama. The same isobath is within 100 miles of the coast for southern Texas and the shoreline between New Orleans and Alabama. Thus the U.S. could conceivably permit unattended nuclear power plants to be used on the sea floor at the maximum depths currently envisioned for such plants, while avoiding the problems of using these power supplies in international waters.

During most of the year, with the exception of hurricane season, relatively mild weather and sea conditions exist in the Gulf. Only the Pacific coast, of the four U.S. offshore areas, is as favorable or better. Platforms are currently designed to withstand hurricane level winds and seas, but even so these designs are generally cheaper to build than platforms designed for the North Sea at equivalent depths. Furthermore, considerable experience has been amassed on a variety of plat form designs in Gulf waters over the last 30 years. This type of data base, which does not exist for the Atlantic and arctic offshore areas, is of significant value in designing platforms for greater depths in the Gulf of Mexico.

Although it would be helpful to present estimates of petroleum reserves in the Gulf area for depths out to 3,000 feet, no data exist which include this depth. Data for all U.S. offshore areas exist at depths up to 200 meters (656 feet), however. ${ }^{1}$ Of the three categories listed in the table below, the degree of uncertainty increases very significantly from left (demonstrated reserves) to right (undiscovered recoverable resources).

The total of all three categories is roughly 8 billion barrels at the lower level, and 13 billion barrels using the higher forecast. In the final column, the percentages decline from $30^{\circ}$ c to $17^{\circ} \mathrm{c}$ because Alaskan areas dominate at the $5^{\circ} \mathrm{c}$ level.

TABLE IV: GULF OF MEXICO PETROLEUM POTENTIAL

\begin{tabular}{|c|c|c|c|}
\hline & $\begin{array}{c}\begin{array}{c}\text { Demonstrated } \\
\text { Reserves }\end{array} \\
\end{array}$ & $\begin{array}{l}\text { Inferred } \\
\text { Reserves }\end{array}$ & $\begin{array}{c}\text { Undiscovered } \\
\text { Recoverable } \\
\text { Resources }\end{array}$ \\
\hline Gulf of Mexico: & $2.26 \times 10^{9} \mathrm{bbl}$ & $2.4 \times 10^{9} \mathrm{bbl}$ & 3 to $8 \times 10^{9} \mathrm{bb|}$ \\
\hline Percent of offshore & $64 \%$ & $89 \%$ & $30 \%, 17 \%$ \\
\hline
\end{tabular}

"Probabilities are associated with these numbers. Quoting directly from Reference 1. "The low value of the range is the quantity associated with a $95 \%$ probability that there is at least this amount. The high value is the quantity with a $5 \%$ probability that there is at least this amount." 


\section{The Pacific Coast}

This area is the only other offshore U.S. area with a significant production history. As of 1974 roughly 1.5 billion barrels had been withdrawn from the lower Pacific coast, compared to 4.1 billion barrels from the Gulf. The potential for petroleum discoveries in the Pacific is comparable to the Gulf of Mexico, however, as shown below.

TABLE V: PACIFIC COAST PETROLEUM POTENTIAL

\begin{tabular}{|c|c|c|c|}
\hline & $\begin{array}{c}\text { Demonstrated } \\
\text { Reserves } \\
\end{array}$ & $\begin{array}{l}\text { Inferred } \\
\text { Reserves } \\
\end{array}$ & $\begin{array}{c}\text { Undiscovered } \\
\text { Recoverable } \\
\text { Resources } \\
\end{array}$ \\
\hline Pacific Coast: & $1.12 \times 10^{9} \mathrm{bbl}$ & $.2 \times 10^{9} \mathrm{bbl}$ & 2 to $5 \times 10^{9} \mathrm{bbl}^{*}$ \\
\hline Percent of offshore & $32 \%$ & $7 \%$ & $20 \%, 10 \%$ \\
\hline
\end{tabular}

" $95 \%$ and $5 \%$ probabilities, as explained in Table IV; data base is limited by a maximum depth of 200 meters.

Depth increases rapidly off the Pacific coast. For example, the 1,000 meter isobath is within 100 miles of the shore along the entire Washington-to-California coast. Depths of 2,000 meters can be found within 200 miles of the shoreline.

The political or legal environment relative to offshore oil production on the West coast is not as favorable to oil producers, compared to the Gulf of Mexico. Although federal laws apply for most of the 200 mile limit, state laws are dominant in the first three miles from shore ${ }^{4}$ and on the shore itself. It is here that local opposition to additional refineries and/or unloading facilities can be channeled effectively into legal denials or constraints. As a result of this political or legal environment, the trend for offshore development in the future will probably incorporate some combination of platforms, subsea production systems, processing vessels and single-buoy moorings - all in federal waters.

Weather and sea conditions off California (where most Pacific coast oil activity is located) are the mildest of the four U.S. offshore areas. However, developers in this region must contend with the likelihood of earthquakes. This requires special well construction techniques to minimize the possibility of leakage on the sea floor, and seismic considerations in platform design.

\section{The Alaskan Coasts}

There are five coastal areas in Alaska to discuss. These include offshore areas of the Beaufort Sea, the Chukchi Sea, the Bering Sea, and the Pacific Ocean; areas adjoining the latter have been split into the mainland and the Aleutian Island chain. Figure 3 is a simplified map of this state and the seas bordering it.

4. Texas and Florida have 10.3 mile limits. 


$$
1
$$


The Beaufort Sea coast of Alaska runs from Point Barrow eastward to the U.S.-Canadian boundary near Gordon. Permanent polar ice is within approximately 100 miles of the coast along the entire length. The remaining strip of sea between permanent ice and land shrinks to zero (solid ice) during most of the year, opening for only a few months in late summer. Interestingly enough, the 1,000 meter isobath roughly parallels the permanent polar ice line. Thus there are two constraints on potential SNPS employment in the Beaufort Sea area, depth and permanent ice; these would limit use to distances 100 miles or less from shore.

Geologists rank the Beaufort Sea area highest in petroleum potential, but no published data exist solely for this coastal region. Rather, the U.S.G.S. has combined part of the Chukchi Sea offshore areas with the Beaufort Sea, and estimated that 2 to 19 billion barrels ${ }^{5}$ of petroleum may be found in northern Alaska offshore areas.

The Chukchi Sea offshore area is relatively shallow. Within either of two constraints, the permanent polar ice and the 200-mile limit, its depth is 200 meters or less. Despite the favorable depth, potential problems exist in this area because the U.S. and Russia have not agreed to boundary lines for most of the Chukchi Sea. This controversy applies particularly to the Navarin Basin, which is regarded as an extremely favorable area for petroleum accumulation. Furthermore, disputes between the federal government and the state of Alaska on Continental Shelf boundaries have not been resolved. Oil production from the Chukchi Sea offshore area can not proceed until such questions are resolved.

The Bering Sea borders western Alaska from the Bering Strait to the northern side of the Aleutian Island Arc. The offshore area from Fort Randall (near the end of the Alaskan Peninsula) north to the Bering Strait is also relatively shallow. Depths within the 200 mile limit or the Russian border are 200 meters or less.

Estimates of petroleum potential for part of the Chukchi Sea (that part not included in the previous estimate for northern Alaska) and the Bering Sea have been made by the U.S.G.S. This particular combined area is the lowest in potential, ranging from 1 to 4 billion barrels. ${ }^{6}$ For comparison, the Prudhoe Bay field (adjoining the Beaufort Sea) is estimated to contain roughly 9 billion barrels of petroleum.

The Aleutian Island Arc offshore areas are distinctly different from the areas discussed previously. First, the depth increases rapidly moving away from shore. Within 50 miles on either side (Bering or Pacific), depths of 2,000 meters can be found. This characteristic applies from Fort Randall to Attu Island, the westernmost Alaskan island, a distance of roughly 800 miles. Second, seismic activity is relatively high in these areas. This implies that field development costs associated with casing/cementing and platforms will be higher for the Aleutian region than other Alaskan areas.

5. As in the previous estimates, probability levels are $95 \%$ and $5 \%$, respectively.

6. The probability levels associated with these estimates are $75 \%$ and $25 \%$, respectively; see Reference 1 for the U.S.G.S. rationale. 
With the exception of the Gulf of Alaska, which is regarded favorably by oil firms, petroleum potential is generally thought to be relatively low in the southern Aleutian offshore area and along the Pacific coast of southwestern Alaska. The U.S.G.S. estimates total petroleum resources at $1-6$ billion barrels.

It may be helpful to summarize the total potential of Alaskan offshore areas at this time. Table VI lists the expected resources by category, in the same format as Tables IV and V; the depth limitation ( $\leq 600$ meters) still applies. The totals shown here reflect proper statistical summation of the data, as opposed to a simple arithmetic summation.

TABLE VI: ALASKAN OFFSHORE PETROLEUM POTENTIAL.

\begin{tabular}{|c|c|c|c|}
\hline & $\begin{array}{c}\text { Demonstrated } \\
\text { Reserves } \\
\end{array}$ & $\begin{array}{l}\text { Inferred } \\
\text { Reserves } \\
\end{array}$ & $\begin{array}{c}\text { Undiscovered } \\
\text { Recoverable } \\
\text { Resources } \\
\end{array}$ \\
\hline Alaskan Coast: & .15 billion bbl & .1 billion bbl & 3-31 billion bbl* \\
\hline Percent of offshore & $2 \%$ & $4 \%$ & $30 \%, 64 \%$ \\
\hline
\end{tabular}

*These estimates are associated with probability levels of $95 \%$ and $5 \%$, respectively.

Despite the magnitude of potential resources, it should be emphasized that Alaska's extreme remoteness and climate will have a tempering effect on development. All of the following cost items are higher than corresponding costs associated with field development and crude production in the contiguous United States:

- Labor and support items

- Material transport (U.S. to Alaska)

- Wells and platform design (in the Aleutians)

- Crude transport (Alaska to U.S.)

In addition to the preceding higher costs, the climate may halt or slow down development operations for months at a time in the northern arctic areas. If tankers are to be employed for transporting crude from isolated fields to terminals such as Prudhoe Bay or Valdez, as opposed to transport using pipelines, climatic conditions in the north may prohibit shipping operations for several months per year. Exploratory drilling in the Beaufort Sea offshore area is presently limited to about three months per year; it is frozen during the remaining months.

Icebergs present a dual threat to oil field development in arctic offshore areas which, it is worth recalling, have the highest estimated petroleum resources. The dual nature consists of damage to platforms through collisions, and scouring of the sea floor. At present, oilmen drilling off Greenland deal with potential iceberg collisions in either of two ways. The first approach is

7. The probability levels are $95 \%$ and $5 \%$, respectively. 
diversion, which is used for icebergs large enough to cause damage to the drillship yet small enough to be diverted off course by other ships. Diversion is used predominately. When the icebergs are too massive for such tactics and a collision appears imminent, the drillship suspends operations and moves out of the way. It is quite evident that only one of these options applies to platforms. Clearly, there is no solution for large icebergs which cannot be diverted.

Scouring of the sea floor is a problem that is widely recognized, but that has received minimal attention in terms of prospective solutions. Scouring takes place in the open sea between land-fast ice and the permanent polar ice, depending on sea depth. Relatively small icebergs can produce gouges in the seabed in water depths of 20 meters. ${ }^{8}$ Whether scouring will occur at greater depths (say 200 meters) in other areas is simply a function of the probability that icebergs measuring roughly 230 meters from keel to summit could appear in that particular area. The next question, assuming one decides to bury all subsea facilities, is how deep a gouge may result? Thus it appears that developers must have very good data on both the probability of occurrence in a given area and the potential range of sizes before any decision is made to commit hundreds of millions of dollars for subsea field drilling and development.

In the preceding paragraphs, we have summarized the petroleum potential for the arctic offshore area, which is estimated to be 2-19 billion barrels. A crucial factor in determining whether this potential can be realized is the distribution of these resources. If the petroleum deposits are dispersed widely, such that no large fields exist, the region may not be developed at all.

Rather than speak of "large" fields, it is more appropriate to mention the concept of minimum-economic-field size. ${ }^{9}$ This is an approach used by some oil companies, based on all anticipated development costs in a given area, to fix the lower limit of required oil production (over the field lifetime) for a field to be profitable. In the hypothetical field example of the preceding section, total production was about 330 million barrels. This figure is in the range of a "giant" field, commonly defined as at least 500 million barrels. It is our impression that isolated fields of less than giant size would not warrant development in arctic offshore areas. As one oil company representative stated, "Any fields smaller than 'giant' size ... may be 'geological successes but commercial failures' in some arctic offshore basins.",(3)

Three major points have emerged from our discussions with oil company personnel on Alaskan offshore field development. In consideration of the preceding difficulties and higher costs, they assert that:

1. Only large fields can be economically developed, in light of the higher-than-normal "front-end" costs;

2. Arctic offshore areas will be developed only after conventional offshore areas have been developed; and

3. Ice-related problems will require more attention.

8. Land-fast ice generally extends out of depths of 10-20 meters. ${ }^{2}$

9. See References 3 and 15 for additional discussion of this concept. 
We would add that transporting crude from remote fields (as discussed above) to terminals is a fourth major problem. In summary, the complexity and extent of problems associated with arctic offshore oil production are such that we cannot reasonably estimate when future development might take place.$^{10}$ It is conceivable that these problems, taken together, might preclude development of offshore arctic areas.

\section{The Atlantic Coast}

In the process of estimating potential petroleum resources within a given area, the U.S.G.S. is often aided by data on existing fields and exploratory wells. The absence of such data in frontier areas makes the estimation process more uncertain. Due to a lack of petroleum production data, the Atlantic Coast may be considered a frontier area in terms of future petroleum resource recovery. The table below reflects this situation.

TABLE VII

ATLANTIC COAST PETROLEUM POTENTIAL

$\begin{array}{lccc} & \begin{array}{c}\text { Demonstrated } \\ \text { Reserves }\end{array} & \begin{array}{c}\text { Inierred } \\ \text { Reserves }\end{array} & \begin{array}{c}\text { Undiscovered } \\ \text { Recoverable } \\ \text { Resources }\end{array} \\ \text { Atlantic Coast: } & 0 & 0 & 2-4 \text { billion bb/* } \\ \begin{array}{l}\text { Percent of offshore } \\ \text { U.S. Total: }\end{array} & 0 & 0 & 20 \%, 9 \% \\ \text { * The probability levels associated with these estimates are } 75 \% \text { and } 25 \%, \text { respectively; from Reference } 1 .\end{array}$

It is evident that this area, at best ( 4 billion barrels), has the lowest potential resources of the four offshore areas. One factor enhances the value of these resources, however; proximity to refineries and ultimate markets. Refining plants are concentrated in the New Jersey-Delaware coastal areas, while the entire Northeast is a major market for petroleum products. Proximity is thus only strictly applicable to northern and mid-Atlantic offshore areas. However, even for fields which may be developed off the Georgia-Carolina coasts the combined field/refinery/market distance is significantly less than for Gulf of Mexico fields feeding (ultimately) the northeast. Oil companies have exhibited strong interest in Atlantic offshore development as a result of these considerations.

With the exception of a small area between Nova Scotia and Cape Cod, the 1000 meter isobath is within 200 miles of the Atlantic coast from the Cape down to Savannah, Georgia. From Long Island to a point near Wilmington, North Carolina, the same isobath is within 100 miles of the shore. Wind and sea conditions are more severe than in the Gulf and offshore California, on average, and hurricanes are a possibility anywhere in offshore Atlantic areas during late summer to late fall. The northern Atlantic has more severe storms than southern areas, but the North Sea environment is harsher than either. Thus development by conventional means (platforms) or using advanced methods (subsea completions) should be possible at costs comparable to or less than North Sea development.

10. Specifically, fields beyond land-fast ice and in depths greater than 60 feet where development from man-made islands is not feasible. 
There are several significant problem areas developers must face if Atlantic offshore petroleum production is to be achieved. The first is that individual state governments and environmental groups must be convinced that the probability of environmental damage to coastal areas due to oil spills and leakage is acceptably low, by their standards. Another special interest group is the Atlantic fishing industry, both Canadian and American. They will require assurance that the fishing industry can coexist with oil field development, and in particular that the risks of long-term damage to major fishing areas are minimal. If these problems can be solved, the technical means to achieve development can be readily employed.

\section{FUTURE TECHNOLOGY}

\section{Platforms}

Conventional platforms fall into either of two categories. The first type is the steel template or jacket platform, which is common in the Gulf of Mexico and offshore California. The largest template platform currently in use was designed by Exxon for 850 foot depths off southern California. (4) Designs of platforms for 1000 foot depths have been analyzed. Present projections are that 1200 foot depths would be the maximum for this type of platform, and then only under moderate sea conditions. ${ }^{(b)}$

The second alternative is a gravity-type platform, usually of reinforced concrete construction, which relies on its own dimensions and great weight for stability in rough seas. These platforms (often combined with large storage capacity undersea as part of the structure) have been used mainly in the North Sea at depths on the order of 300 feet (minimum) ${ }^{(6)}$ We do not intend to discuss either of these concepts further; they have been mentioned solely as a starting point for advanced platform discussion. References 5 and 6 can provide additional details on conventional platforms.

Exxon's Production Research Division is pursuing an interesting concept for platforms to be located in 1500-2000 depths. Their design, known as a "compliant tower," is essentially a relatively slender steel template-type tower which is supported vertically by the sea floor and horizontally by a large number $(\sim 20)$ of anchored cables. This tower is designed such that cable restoring force is directly proportional to horizontal displacement at the surface due to wave and/or wind action. Cable tension would be within conservative limits under the simultaneous combination of 100 foot waves, $100 \mathrm{mph}$ winds and a 3 knot current. ${ }^{(7)}$ Figure 4 shows the present design for 1500 foot depths. Exxon has a 1/5th scale model of this design under test in the Gulf of Mexico at this time. Reference 7 provides a thorough discussion of this concept, which Exxon favors for depths in the $1500-2000$ foot range.

Deep Oil Technology (DOT) is a major developer of the "Tension Leg" platform concept, which is illustrated in Figure 5. The platform itself has very high buoyancy and is pulled down into the water a specified distance by cables attached to deadweight anchors. The name "tension leg" derives from the cables, which are always under tension. North Sea ${ }^{11}$ design criteria are 103 foot waves, $90 \mathrm{knot}(104 \mathrm{mph})$ winds, and $2.5 \mathrm{knot}$ current. ${ }^{(8)}$ DOT maintains that this platform can be designed to be virtually free of vertical motion (heave, pitch and roll), while retaining acceptable lateral displacements. Like Exxon, they have built a reduced scale (one-third size) prototype for testing purposes and installed it at sea.

11. The northern North Sea; the platform will survive these conditions. 


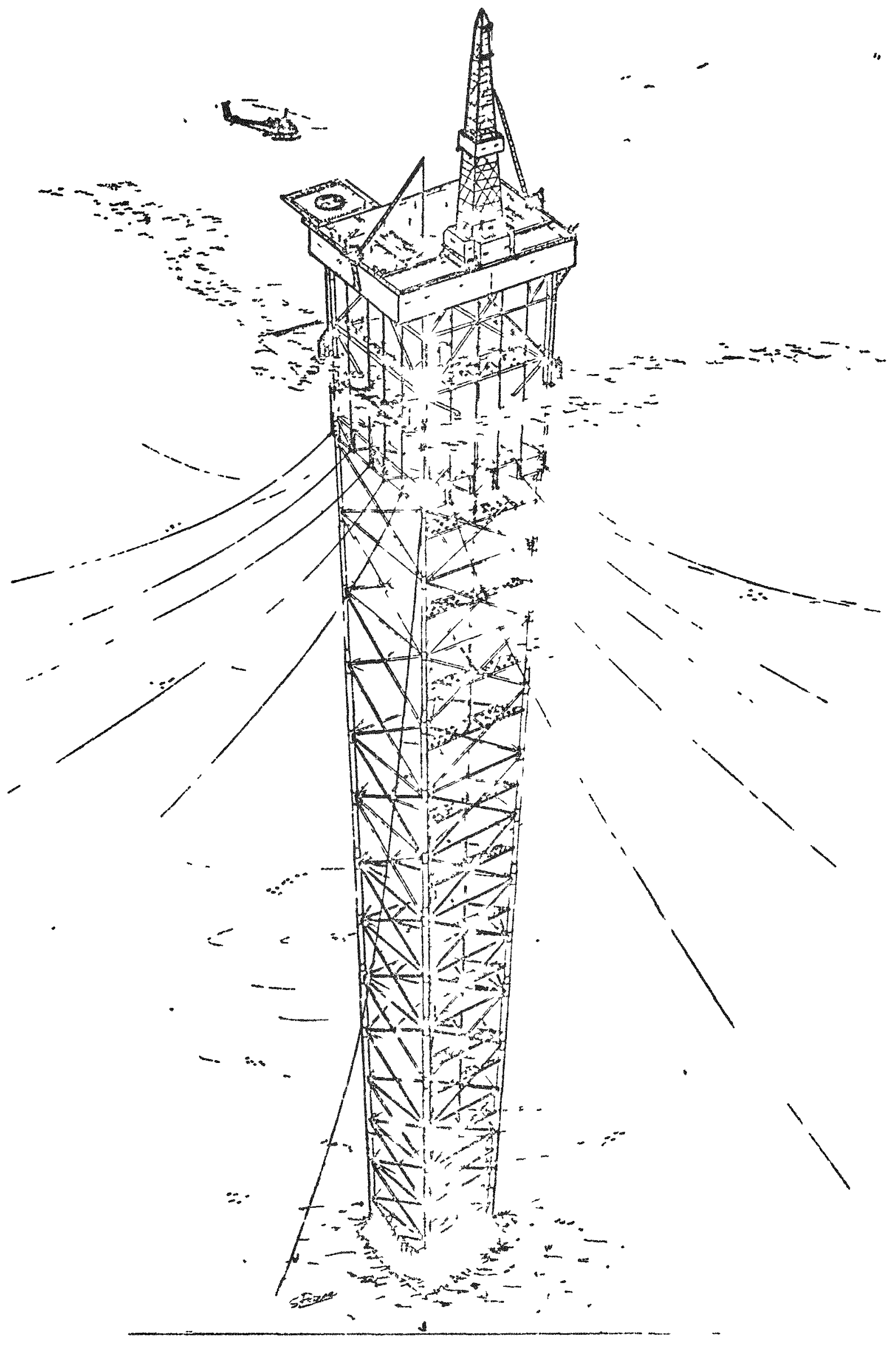

FIGURE 4 SKETCH OF 1500 FOOT COMPLIANT TOWER 


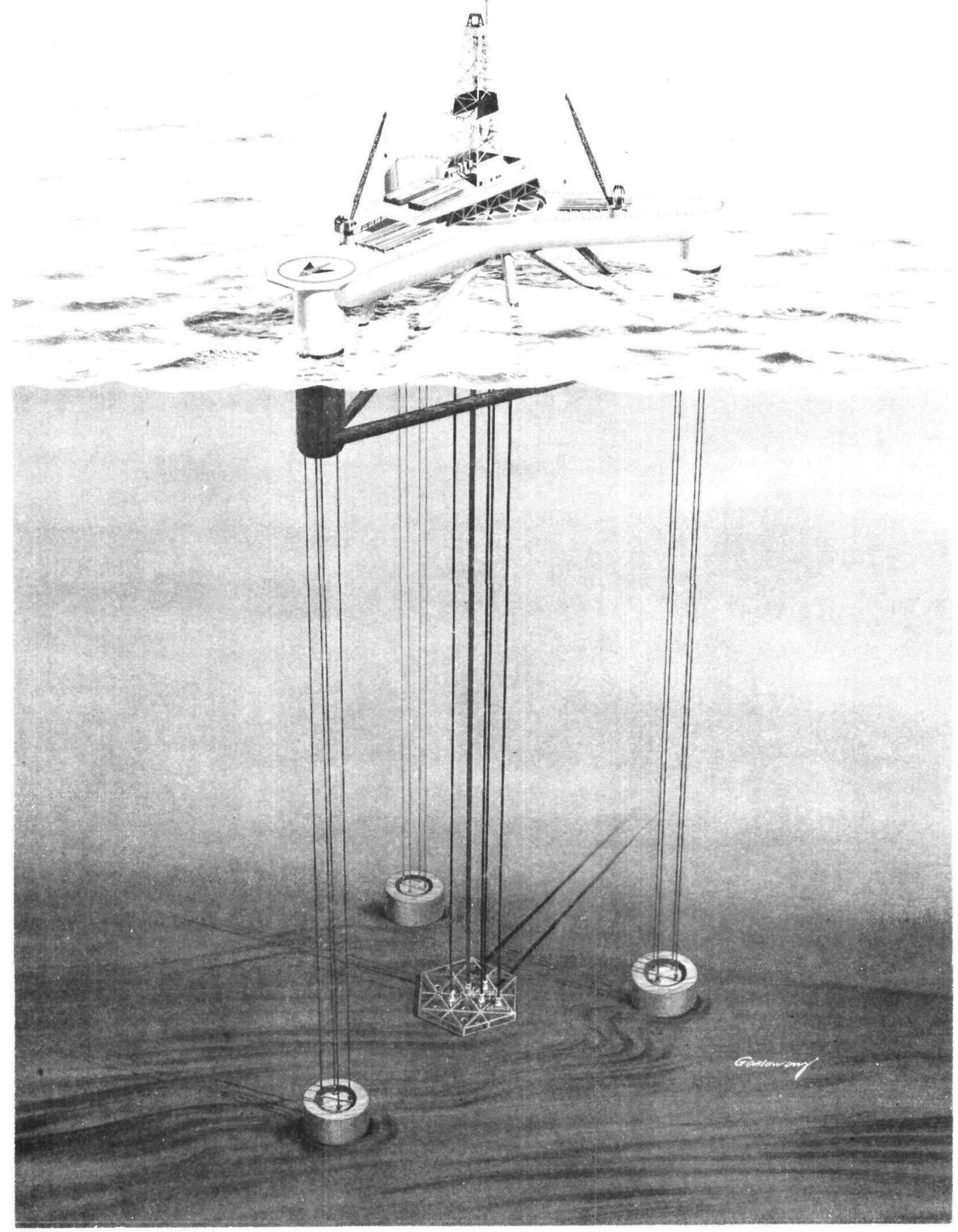

FIGURE 5 TENSION LEG PLATFORM 
The following TLP advantages, relative to conventional platforms, are cited by the designers:

1. Cost is not significantly affected by water depth;

2. The TLP has a minimal response to earthquakes;

3. Can be relocated with comparative ease;

4. Platform removal and cleanup is greatly simplified.

Subsea production equipment would be employed on the sea floor, in a template located directly beneath the platform. Flow from each well would normally be controlled by a tree ${ }^{12}$ on the platform, although subsea trees can be installed on the sea floor for back-up capability as desired. Commingling of production fluids at the template is also an option. After separation on the platform, crude is transferred back down to the template and thence to a pipeline or loading terminal.

In the case of a hard sea bottom, the deadweight anchors would rest directly on the seabed as shown in Figure 5. For soft sea bottoms, deadweight anchors in the form of cylinders would be cemented in place using piling design techniques. ${ }^{(8)}$

DOT has analyzed the TLP concept at depths of 3000 feet without finding technical limitations. The concept is also capable of being scaled down in size and cost from the North Sea design to meet less demanding wind and wave conditions.

In summary, the TLP appears to be the only platform option in 2000-3000 foot depths. The compliant tower seems to have an advantage in terms of greater payload capacity (according to current designs). at 1500 foot depths, but is at a disadvantage in terms of removal and seismic sensitivity. The main point of this discussion, however, is that companies such as Exxon and DOT have concepts, designs and prototypes for platforms capable of installation in depths up to 3000 feet - the SNPS design depth. Thus field developers would still apparently have a platformbased production method as an option.

\section{Subsea Production Systems}

Two basic types of subsea production systems have evolved in recent years. The "template" approach utilizes a compact steel framework on the sea floor, through which all wells (typically 16-20) are drilled. This is a centralized approach and suitable for large, compact fields. The template may contain manifolding to combine the output of all wells, separators, and other production apparatus. Exxon is continuing development of a full-function template base/manifold, as described, in addition to a service capsule which permits routine maintenance tasks to be performed from a small surface support vessel. The third item, which completes the system, is called a "production riser". This is essentially an articulated pipe and cable combination extending from a fixed base on the sea floor to a buoy/terminal on the surface. Its function is to bring well output to the surface, carry fluids to the wells for reinjection (if desired), and transmit both electrical power and control signals to the base/manifold. A vessel on the surface would process the well output, provide a limited storage capacity, and supply power. Reference 10 provides a thorough description of the Exxon system; Reference 8 describes the Deep Oil Technology system. SEAL has been examining several types of systems, which are reported in a paper by Adams, et al. ${ }^{(1)}$ For an extensive survey of all present and near-term subsea production systems, Reference 12 is highly recommended.

12. The so-called "Christmas troes", which are complex valve assemblies. 
The second type of subsea system might be called "dispersed." LPS in particular has developed this concept, which was described earlier in this report. It consists of a central manifold center and dispersed wells. All wells would be within reasonably short distance (several miles) of the manifold center, but spread out and located as field characteristics dictate for most efficient development. Flowlines connecting the center with each well would carry inbound well fluids, gas or water back for injection into the wells (if desired) and permit through-flow-line (TFL) maintenance.

LPS has not designed a production riser, choosing instead to rely upon field applications where a platform or processing facility is within reasonable pumping distance. The SNPS unit would supply pumping power, of course. The AI summary report discussed earlier provides a sufficient description of the LPS subsea system. However, the Oil and Gas Journal of June 21, 1976 contains a far more thorough account of the system and a current application in Brazil. 


\section{COMPETITIVE ALTERNATIVES TO THE SNPS}

\section{A. PLATFORM/VESSEL-MOUNTED POWER SUPPLIES}

Our initial approach to comparing a SNPS with other power supplies was to require that the alternatives be capable of duplicating the projected SNPS performance in terms of power production and maintenance, i.e. producing $3 \mathrm{MW}$ continuously and being refueled only every four years. This comparison is not unreasonable for a shore-based substation/cable combination, which is fed by a utility grid, but it is unreasonable when applied to platform-mounted internal combustion (IC) prime movers if one also requires a separate and sufficiently large fuel supply for these units. An example will point out the problems.

As a first step, let us assume that refueling a platform-mounted turbine driven generator in the Gulf of Mexico once a year is permissible. The platform would have to be capable of storing 62,000 barrels of oil if the turbine is $25 \%$ efficient. This quantity of oil weighs 10,040 tons and occupies roughly 350,000 cubic feet. When allowance is made for fuel storage tanks and bracing to handle the weight, the platform would be about three times as large as a conventional production platform in the Gulf. Rough estimates of the cost of a conventional template platform for the generator and fuel tanks in 400 feet of water are in the neighborhood of $\$ 20$ million dollars; a tension-leg (floating) platform would be roughly $\$ 40$ million.

The upshot of this exercise is that the cost of a platform-mounted generator with a year's fuel supply would be regarded as prohibitively expensive by a field developer. Similarly, the cost of a platform with a four-year fuel supply would be so high as to be out of the question; thus the "SNPS equivalent" approach is not feasible here.

In the preceding discussion we assumed implicitly that fluids and gases taken directly from the wells would not be suitable for use as fuel in the prime movers. However, if the field fluids and/or gases are capable of being processed with a minimum of difficulty into suitable fuels, the situation changes drastically. Our discussions with oil company personnel lead us to believe that, more often than not, a suitable fuel can be made available from the production stream. Under these circumstances a turbine or diesel-powered generator, in combination with limited and basic processing capacity (about 160 barrels or $930 \mathrm{MCF}$ per day), could be added to conventional production platforms thereby achieving reliable baseload power at minimal cost. Exxon plans to use this exact approach on their processing/storage vessel off southern California. ${ }^{(13)}$ The main point here is that whenever a structure exists on the surface in or near a producing field, and when the production can be treated for consumption in an IC engine on the structure, it is a straightforward task to generate low-cost electricity.

Gas would quite probably be produced in sufficient quantity for a $3 \mathrm{MW}$ turbine unit from any field producing 50,000 BOPD of crude. Even if the GOR were as low as 20 (recall it was 1,000 for the hypothetical field example), this would result in 1,000 $\mathrm{MCF}$ of gas per day. It appears, therefore, that gas is a sound assumption for fuels. Under this assumption, we need not consider the cost of equipment for processing small quantities of production crude into a liquid fuel suitable for turbines or diesel engines. 
The question of what cost or value should be assigned to fuel produced in this manner has been raised by AI. If the well output contains gas, and no transmission pipeline exists, the developers would probably flare it off or reinject it into the reservoir (depending on the quantity produced). In this case, the gas would probably be considered "free." On the other hand, if a pipeline existed the gas might be costed at the receiving terminal price.

Our answer to the question is that both values will be used. In the following section, we will indicate what annual operating costs would be at $\$ 2.24 / \mathrm{MCF}^{1}$ when a fuel cost is appropriate and consider gas "free" when that is appropriate.

From contacts with several manufacturers of gas turbines and diesel units, we can state that 2.5 MW "packaged" units capable of running three or four years continuously are presently available. The cost is about $\$ 400,000$ for a diesel-powered generator, and roughly $\$ 500,000$ for a turbine-powered unit. The permissible time for continuous running is a function of fuel quality, with natural gas preferred as the cleanest fuel. Poor quality fuels such as residual oil or complex gas mixtures from producing oil wells would require more frequent maintenance.

At this point, we have established a power supply on the surface. The remaining task is to investigate cable systems which can effectively transmit power down to the SNPS unit. Cable systems will be discussed following a brief description of shore-based power supplies.

\section{B. SHORE-BASED POWER SUPPLIES}

The first choice for a reliable source of electric power on shore would be a substation tied into the local utility. We assume the oil field developers would purchase the transformers, switches, circuit breakers and control apparatus comprising the substation. A rough estimate for this facility would be $\$ 15 / \mathrm{kVA}$. Allowing for the additional reactive power requirements of cable systems, the substation equipment would be approximately $\$ 50,000$. If an identical back-up system were desired, the cost would double.

Alternatives to the substation include a diesel-powered generator and a gas turbine-powered generator. The diesel is more efficient (32\%) than the gas turbine unit (25\%) and also has a lower initial cost per $\mathrm{kW}$ in the 2.5 to $3.0 \mathrm{MW}$ range.

Maintenance costs for each unit are typically a small fraction of fuel cost. For example, oil at $\$ 12 / \mathrm{bbl}$ translates to $22 \mathrm{mills} / \mathrm{kWh}$ (fuel cost alone) for the diesel, and $28 \mathrm{mills} / \mathrm{kWh}$ for the turbine. Operating and maintenance costs are on the order of 2.5 to $3.5 \mathrm{mill} / \mathrm{s} / \mathrm{kWh}$, and are slightly dependent on fuel quality.

The gas turbine system is generally smaller and lighter than a diesel system, and has the additional advantage that both gaseous and liquid fuels can be used with minor adjustments to the burner section. However, the lower capital cost and higher operating efficiency of diesel systems would make them the preferred system in general if fuel costs were equal. As cited earlier, it is quite probable that gas would be available for fuel. It is quite improbable that well output could be treated for use in diesels. Therefore, we have chosen gas turbines as the most appropriate prime movers for generating systems.

1. Equivalent to oil at $\$ 13 / \mathrm{barrel}$. 
The actual output required from the power supply to deliver $3.0 \mathrm{MW}$ at the load will vary as a function of cable length due to resistive and dielectric losses. Therefore, in order to permit more accurate cost estimation we will use the following "per unit" figures which are applicable to turbine/generator sets in the 1.5 to $2.5 \mathrm{MW}$ range. Data for diesel/generator sets are also presented, since there may be some potential application (e.g, on the Gulf coast) where fuel oil and gas are comparably priced.

The systems described in the tables are complete and ready for connection to step-up (transmission) transformers. All units would have automatic startup capability. In normal operation, units on standby would have sufficient capacity to ensure that failure of one on-line unit would result in nothing more than a short-term interruption of power to the cable system.

\title{
TABLE VIII
}

\section{TURBINE/GENERATOR SYSTEM DATA I1977\$1}

\author{
Unit Cost: $\quad \$ 200 / \mathrm{kW}$ for self-contained units \\ Layout: $\quad 2-4$ units with a common control/switching center \\ Heat Rate: $\quad 13,650 \mathrm{Btu} / \mathrm{kWh}$ \\ Installation Cost: $\quad \$ 100,000-\$ 150,000 *$ \\ O\&M Cost: $\quad 3.5 \mathrm{mills} / \mathrm{kWh}$ \\ Weight: $\quad 20$ tons, complete with control cubicle (2.5 MW unit) \\ Size: $\quad 24^{\prime}$ long $\times 8^{\prime}$ high $\times 7^{\prime}$ wide (2.5 MW unit) \\ * Installation cost is a function of site-specific details and the number of units \\ employed. This range is an Arthur D. Little, Inc., estimate based on compar- \\ able system data.
}

TABLE IX

\section{DIESEL/GENERATOR SYSTEM DATA (1977\$)}

\author{
Unit Cost: $\quad \$ 180 / \mathrm{kW}$ for self-contained units \\ Layout: $\quad 2-4$ units in common housing \\ Heat Rate: $\quad 10,500 \mathrm{Btu} / \mathrm{kWh}$ \\ Installation Cost: $\quad \$ 100,000-120,000$ in U.S." (freight, site prep., all controls, housing) \\ O\&M Cost: $\quad 2.5 \mathrm{mills} / \mathrm{kWh}$ (all scheduled maintenance, 20 year life) \\ Weight: $\quad 38$ tons, complete with control cubicle (2.5 MW unit) \\ Size: $\quad 33^{\prime}$ long $\times 10^{\prime}$ high $\times 7^{\prime}$ wide.
}

\footnotetext{
*Installation cost is a function of the number of units employed and site-specific details. The lower estimate is a manufacturer's quote for a $5.0 \mathrm{MW}$ two-unit system.
} 


\section{CABLE POWER TRANSMISSION SYSTEMS}

The proposed SNPS unit is designed for a single, demanding task: to supply $3.0 \mathrm{MW}$ of electric power, reliably, to the submerged pumping station described earlier. For a cable system to be competitive, it must deliver $3.0 \mathrm{MW}$ at the load with the same reliability and at equal or less cost. We believe the power sources discussed in the preceding sections are as reliable as the SNPS, and that the cable systems to be described here would be satisfactory also. Therefore, the primary purpose of this section is to determine whether a cable system is cost competitive at a given transmission distance or not. Cost competitiveness will be based upon the total initial cost (capital cost) and annual operating costs.

Both ac and dc systems were evaluated over a range of distances. Table $\mathrm{X}$ describes the most economical system for each distance. It is clear that ac is preferred at 5 and 10 miles; at 20 miles either ac or dc could be used. The ac system is slightly cheaper in total initial cost, but more expensive to operate due to higher cable losses. Table XI compares real power, reactive power and losses for each system.

Every system has backup capability, so that if a cable is damaged or fails full power can be restored quickly. The ac systems use two 3 -conductor cables so that each cable is a three-phase $(3 \phi)$ circuit. If one cable fails, the other can carry the full load. The dc systems use three singleconductor cables, of which only two are required for a full-power circuit at any given time. Therefore, the loss of one cable will not prevent full power from being delivered. Cable failures, incidentally, are caused more frequently by outside intervention (such as a dragging anchor) than by internal (material) failure.

In systems 1 through 5 , the transmitting terminal was assumed to be based on shore. The receiving terminal was assumed to be built into the pumping station, located in 1200 feet of water at the specified distances. If the transmitting terminal were to be platform-mounted for any of these systems, installation cost would decrease slightly since the cost of cable burial in the shore area could be avoided. Systems 6 and 7 represent open-water systems, with platform-mounted transmitting terminals. Their costs would increase very little if shore-based terminals were chosen instead.

The cost of de terminals at the receiving end $(\$ 150 / \mathrm{kW})$ is considerably higher than transmitting terminals $(\$ 40 / \mathrm{kW})$ because there is no commutating capacity at the load, which would normally exist if the cable fed an ac grid. A self-commutating inverter is needed at the load for these systems. Our estimate of $\$ 150 / \mathrm{kW}$ is based on a working figure of $\$ 100 / \mathrm{kW}$ for units on the order of $100 \mathrm{MW}$.

An important assumption in Table $\mathrm{X}$ is the figure of $\$ 20,000$ per mile for installation cost when the distances are relatively short ( 20 miles or less). We have discussed this particular figure with a major manufacturer and installer of subsea cables, ${ }^{141}$ and have concluded that it is an appropriate estimate for the general nature of these systems. Cost per mile is considerably less at longer distances when large cable-laying ships can be used.

In the arctic offshore areas of the Beaufort and Chukchi Seas, cost per mile would be highly site-specific, and a function of the distance from a cable manufacturing plant to the site. Manufacturers are hesitant even to speculate on a unit cost estimate for this area. However, the problems associated with arctic offshore field development (specifically fields beyond land-fast 


\section{TABLE X: DESCRIPTION OF CABLE SYSTCAS}

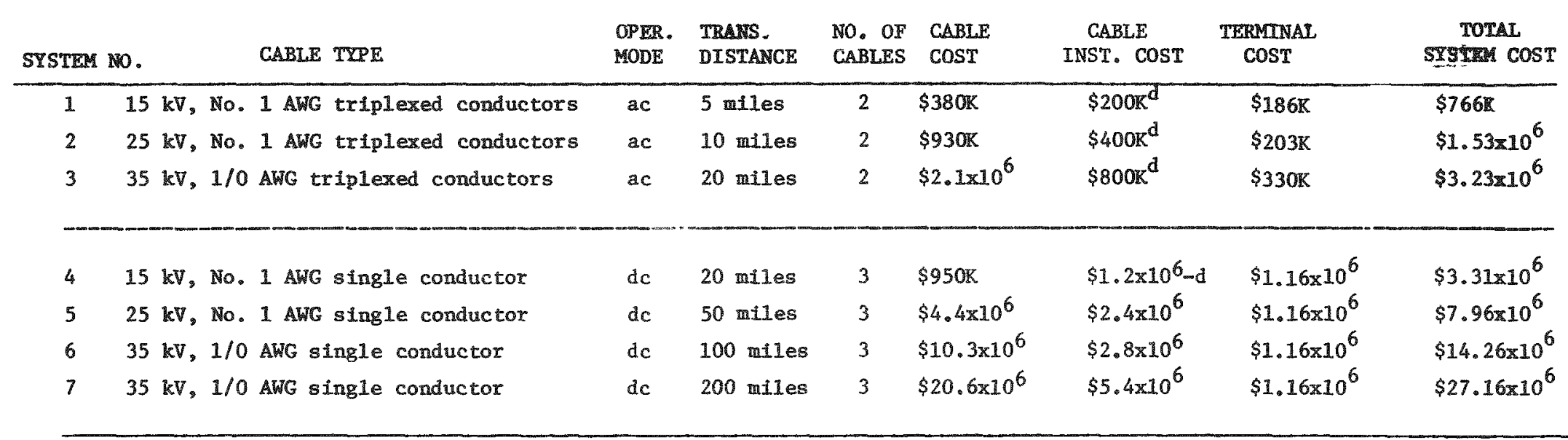

\section{NOTES}

a. All costs are in 1977 dollars.

b. The cost of ac terminals was assumed to be $\$ 15 / \mathrm{kVA}$ at each end.

c. The cost of dc terminals was assumed to be $\$ 40 \mathrm{~kW}$ at the sending end and $\$ 150 / \mathrm{kW}$ at the $10 a d$.

d. Installation cost for short distance was set at $\$ 20,000 /$ mille; it declines with distance as shown.

- The transmitting terminal is based on shore for systems 1-5.

f. Systems 6 and 7 use platform-based terminals.

8. Cable cost data supplied by Simplex Wire and Cable Company, Portsmouth, New Hamphire. 
TABLE XI

CABLE SYSTEMS DATA: $3.0 \mathrm{HW}$ DELIVERED TO LOAD

\begin{tabular}{|c|c|c|c|c|c|c|c|}
\hline $\begin{array}{l}\text { SYSTEM } \\
\text { NUMBER } \\
\end{array}$ & $\begin{array}{l}\text { TYPE OF } \\
\text { SYSTEM }\end{array}$ & $\begin{array}{l}\text { OPERATING }^{1} \\
\text { VOLTAGE } \\
\end{array}$ & $\begin{array}{c}\text { REAL POWER } \\
\text { (SENDING END) } \\
\end{array}$ & $\begin{array}{l}\text { REACTIVE POWER } \\
\text { (SENDING END) }\end{array}$ & $\begin{array}{l}\text { ANNUAL POWER } \\
\text { COST \& } 3 c / \mathrm{kWh} \\
\end{array}$ & $\begin{array}{l}\operatorname{COST} \text { OF } \\
\text { LOSSES } \\
\text { a } 3 \mathrm{c} / \mathrm{kWh} \\
\end{array}$ & $\begin{array}{l}\text { ANNUAL }^{4} \\
\text { FUEL COST } \\
\text { e } \$ 13 / \mathrm{bb} 1 \\
\end{array}$ \\
\hline 1 & $a c$ & $8.9 \mathrm{kV}$ & $3.14 \mathrm{MW}$ & $0.5 \mathrm{MVAR}$ & $\$ 825 \mathrm{~K}$ & $\$ 37 \mathrm{~K}$ & $\$ 841 \mathrm{~K}$ \\
\hline 2 & ac & $14.7 \mathrm{kV}$ & $3.12 \mathrm{MW}$ & 2.1 MVAR & $820 \mathrm{~K}$ & $32 \mathrm{~K}$ & $836 \mathrm{~K}$ \\
\hline 3 & ac & $20.4 \mathrm{kV}$ & $3.31 \mathrm{MW}$ & 7.3 MVAR & $870 \mathrm{~K}$ & $82 \mathrm{~K}$ & $887 \mathrm{~K}$ \\
\hline 4 & $\mathrm{dc}$ & $20.5 \mathrm{kV}$ & $3.21 \mathrm{MW}$ & - & $844 \mathrm{~K}$ & $55 \mathrm{~K}$ & $860 \mathrm{~K}$ \\
\hline 5 & $d c$ & $34.0 \mathrm{kV}$ & $3.20 \mathrm{MW}$ & - & $841 \mathrm{~K}$ & $53 \mathrm{~K}$ & $858 \mathrm{~K}$ \\
\hline 6 & $\mathrm{dc}^{5}$ & $47.2 \mathrm{kV}$ & $3.17 \mathrm{MW}$ & - & $833 \mathrm{~K}$ & $45 \mathrm{~K}$ & $849 \mathrm{~K}$ \\
\hline 7 & $\mathrm{dc}$ & $48.1 \mathrm{kV}$ & $3.27 \mathrm{MW}$ & - & $859 \mathrm{~K}$ & $71 \mathrm{~K}$ & $876 \mathrm{~K}$ \\
\hline
\end{tabular}

Notes: 1. The ac voltage indicated is $\mathrm{rms}$ to ground.

2. This column applies if power is purchased from a utility at $\$ .03 / \mathrm{kWh}$.

3. Losses remain relatively constant for system 2 compared to 1 , since the voltage has been raised; in system 3, higher charging currents begin to raise resistive losses. Similarly, losses are kept low in the dc systems by raising the transmission voltage as distance increases.

4. This column is applicable if fuel is purchased at the stated price, and the unit has an efficiency of $25 \%$.

5. The cables for system 6 and 7 can withstand $49.5 \mathrm{kV}$ in normal service. 
ice and in depths greater than 60 feet, where man-made islands are not feasible) are so demanding (as described in Section III) that it is premature to "guesstimate" field development costs. If all subsea completions, and the flowlines, and the pumping station, and the pipeline have to be placed below the seabed to avoid ice scouring problems, then it is unlikely the field would be developed. In summary, for these arctic offshore areas it is premature to analyze field development costs with or without SNPS units and conventional alternatives.

Table XI shows the nature of losses in each system. In particular, note how rapidly the reactive power requirements increase with distance for ac systems. Reactive power "charges up" the cable insulation on each cycle, and does no useful work. It is measured in terms of voltamperes-reactive, or VAR's. A "source" of reactive power is needed at the sending end, but the upshot of this discussion is that additional costs are required above the nominal $3.0 \mathrm{MW}$ equipment required for a dc system.

Up to this point, we have considered power systems capable of supplying $3.0 \mathrm{MW}$ at distances as great as 200 miles. The simple fact is that 40 miles would be the longest distance ${ }^{2}$ between the pumping station and the platform (or processing vessel, or shore terminal), because 3.0 $\mathrm{MW}$ is the maximum power available for pumping 50,000 barrels of oil per day through the pipeline under the conditions specified earlier.

We can conceive of two basic scenarios which are relevant to SNPS applications and alternative power supplies. Scenario A consists of the following situation:

1. The pumping station is located 40 miles from a production platform or vessel.

2. Gas is available from the well output at the platform, and is "free" (variation: see below).

3. Both the platform and pumping station are in depths between 600 and 1200 feet.

Power can be supplied to the pumping station in either of two ways; by a SNPS on the sea floor, or three $1800-\mathrm{kW}$ gas turbine/generator sets on the platform plus a de cable system. Costs would be as shown below:

Type of Cost

Total initial cost (millions)

Total annual cost:
SNPS

$\$ 14.2$

$\$ .92$ million

\section{Gas Turbine System Plus Cable*}

$\$ 7.74$ million

\$.098 million ("free"

fuel $+O \& M$ )

or .954 million"

"See Appendix 5 for detalls of these estimates.

* Gas at $\$ 2.24 / 1000 \mathrm{MCF}$, which is equivalent to ofl at $\$ 13 / \mathrm{barrel}$

2. 40 miles is a nominal figure; the exact distance is a function of height differential between the pumping station elevation, manifold center elevation and the pipeline terminal elevation. 
Clearly, the gas turbine is cheaper to purchase - almost by a factor of two. Its operating cost (primarily fuel) would very likely be negligible, but even if fuel costs were equivalent to oil at $\$ 13 /$ barrel the annual costs would be approximately equal to the SNPS annual cost.

The second scenario, $\mathrm{B}$, consists of the following:

1. The pumping station is located in 900 feet of water, 40 miles from the shore where the pipeline terminal is located.

2. Power is available from a utility at $3 \mathrm{c} / \mathrm{kWh}$ at or near the terminal.

For scenario B, the logical alternative to a SNPS would be a $7000 \mathrm{kVA}(2 \times 3500 \mathrm{kVA}$ systems) substation on shore and a dc cable system. The cost comparison is presented below.

Type of Cost

Total initial cost (millions)

Total annual cost:
SNPS

$\$ 14.2$ million

$\$ .9$ million
Substation Plus Cable*

$\$ 7.19$ million

$\$ .84$ million

"See Appendix 5 for a detalled cost breakdown.

Again, there is no doubt that a conventional system is superior. The capital cost differential is even greater, at $\$$ seven million, and the operating costs are less.

In conclusion, only if one could conceive of a situation where a pumping station had to be loceted roughly 100 miles (or greater) from the pipeline terminal would a SNPS unit be fairly equivalent in capital and operating costs to conventional systems. If we maintain the assumption that oil and water injection pipelines would cost about $\$ 1$ million per mile (together), then the field development cost must rise by $\$ 60$ million for the pipeline. Furthermore, we should assume that pumping stations are needed every 40 miles or so to maintain single-phase flow. The complications may be apparent; more stations, more power supplies, and greatly increased costs with no projected increases in revenue. We are forced to conclude, therefore, that a SNPS unit would not be an economic competitor to conventional power and cable systems in any probable type of offshore oil field environment. 


\section{APPENDICES}

1. References

2. Al Experience with Reactors Using Internal Control Rods

3. Electromagnetic Pump Data

4. Al's Proposed Refueling Base

5. Power Supply Cost Breakdown 


\section{APPENDIX 1: REFERENCES}

1. "Geological Estimates of Undiscovered Recoverable Oil and Gas Resources in the U.S.," U.S.G.S. Circular No. 725, 1975.

2. "Summary Report of the Sediments, Structural Framework, Petroleum Potential, Environmental Conditions, and Operational Considerations of the United States Beaufort Sea, Alaska Area," Open-File Report 76-830 (Preliminary), U.S.G.S., Menlo Park, California.

3. "Economic Feasibility Appraised for Petroleum Search in Remote Regions," L.F. Ivanhoe, The Oil and Gas Journal, December 20, 1976.

4. "Deepwater Capabilities," Exxon Production Research Company, Houston, Texas.

5. "Offshore Drilling and Production Technology - Where Do We Stand and Where Are We Headed," R.L. Geer, presented at the 1973 American Petroleum Institute (API) meeting.

6. "Steel or Concrete Platforms for the North Sea - or Neither?" R.J. Enright, The Oil and Gas Journal, June 30, 1975.

7. "Compliant Tower Approach to Deep Water Platforms," F. Chuck, Exxon Production Research Company, presented at the 1976 Production Department Meeting (API).

8. "General Description of the Tension Leg Platform System," Deep Oil Technology, Inc., a subsidiary of the Fluor Corporation, Long Beach, California.

9. Private Communication, Mr. J.H. Brewer, Manager, Marine Division, Deep Oil Technology (see above).

10. "The Exxon Submerged Production System," Exxon Production Research Company, Houston, Texas.

11. "New Offshore Recovery Advancements for Deep Water Completions," J.R. Adams, et al., Paper No. OTC1834, Offshore Technology Conference, Dallas, Texas, 1973.

12. "Subsea Production Systems Technology - Where Does It Stand and Where Is It Headed," R.L. Geer, presented at the Fifth International Symposium, Celle, West Germany, 1974.

13. "Generators Due Exxon Offshore Storage Vessel," The Oil and Gas Journal, February 21, 1977.

14. Private Communication, Mr. J.C. McIntyre, Vice President, Simplex Wire and Cable Company, Portsmouth, New Hampshire.

15. "Alaska to Lead OCS Output in 10 Years," The Oil and Gas Journal, April 11, 1977. 


\section{SUPPLEMENTARY READING}

The following documents were reviewed as part of this study, and are recommended as additional background material.

"The Worldwide Search for Petroleum Offshore - A Status Report for the Quarter Century, 1947-1972," U.S.G.S. Circular 694, 1974.

"Geologic Framework of the Alaskan Continental Terrace in the Chukchi and Beaufort Seas," A. Grantz, et al., U.S.G.S., Menlo Park, California.

"Reda Pumps for the Petroleum Industry," Reda Pump Company, Bartlesville, Oklahoma.

"Simulation of Hypothetical Offshore Petroleum Developments," H. Lahman, et al., MIT Department of Ocean Engineering, 1974.

“The Economics of Arctic Oil Transportation," J. Lassiter III, et al., MIT Sea Grant Program Report No. MITSG 71-4, 1970.

“Zirconium Hydride Reactor Power Systems for Undersea Oil Field Applications," AI-BD-73-18, 1973.

"A 4000-HP Reactor/Organic Rankine Cycle Power System for Undersea Oil Field Application," AI-73-22, 1973.

"The Application of a Compact Nuclear Power System to Subsea Oil Production," AI-74-20, 1974.

"Survey of Control Rod Drives for Application to the Terrestrial Reactor," IT-652-220-016, 1974.

“Design Report, 3000-kWe Subsea Nuclear Power Plant," AI-AEC-13141, 1974.

"Development Plan, Subsea Nuclear Power System," ER-652-120-001, 1974.

"Subsea Nuclear Power System, Phase I Task, Design and Engineering," Contract AT(04-3)-701, 1975.

"Systems for Nuclear Auxiliary Power, Annual Report, Government Fiscal Year 1975," AIERDA-13163, 1975.

"Zirconium Hydride (SNAP) Reactor Space Power Programs: Summary of Major Activities and Accomplishments," 714-B.54, 1976.

"Systems for Nuclear Auxiliary Power, Annual Report, Government Fiscal Year 1976/TQ," AIERDA-13179, 1976. 


\section{APPENDIX 2: AI EXPERIENCE WITH REACTORS USING INTERNAL CONTROL RODS}




\section{BLANK}


AI REACTOR DESIGNS WHICH USE INTERNAL CONTROL RODS

1 of 2

\begin{tabular}{|c|c|c|c|c|c|c|c|}
\hline \multirow[b]{2}{*}{ REACTOR } & \multicolumn{2}{|c|}{ POWER } & \multirow{2}{*}{$\begin{array}{l}\text { REACTOR OUTLET } \\
\text { TEMPERATURE, }{ }_{F} F\end{array}$} & \multirow[b]{2}{*}{ COOLANT } & \multirow[b]{2}{*}{ MODERATOR } & \multirow{2}{*}{$\begin{array}{l}\text { TYPE OF } \\
\text { FUEL }\end{array}$} & \multirow{2}{*}{$\begin{array}{l}\text { NUMBER } \\
\text { OF FUEL } \\
\text { ELEMENTS }\end{array}$} \\
\hline & Mut & Mule & & & & & \\
\hline $\begin{array}{l}\text { Hallam Nuclear } \\
\text { Power Facility }\end{array}$ & 254 & 76 & 945 & $\mathrm{Na}$ & Graphite & UMo & 137 \\
\hline $\begin{array}{l}\text { Sodium Reactor } \\
\text { Experiment }\end{array}$ & 20 & 5.7 & 960 & $\mathrm{Na}$ & Graphite & U & 43 \\
\hline $\begin{array}{l}\text { Piqua Nuclear } \\
\text { Power Facility }\end{array}$ & 45.5 & 11.4 & 575 & $\begin{array}{c}\text { Organic } \\
\text { (Terphenyl) }\end{array}$ & $\begin{array}{l}\text { Same as } \\
\text { Coolant }\end{array}$ & UMO & 70 \\
\hline $\begin{array}{l}\text { Organic Moderated } \\
\text { Reactor Experiment }\end{array}$ & 16 & 0 & $520-710$ & $\begin{array}{c}\text { Organic } \\
\text { (Polypheny1) }\end{array}$ & $\begin{array}{l}\text { Same as } \\
\text { Coolant }\end{array}$ & $\mathrm{UO}_{2}$-SS & 31 \\
\hline $\begin{array}{l}\text { Proposed Subsea } \\
\text { Power System }\end{array}$ & 10.5 & 3 & 800 & NaK & $\mathrm{ZrH}$ & UZrH & 19 \\
\hline
\end{tabular}




AI REACTOR DESIGNS WHICH USE INTERNAL CONTROL RODS

2 of 2

\begin{tabular}{|c|c|c|c|c|c|c|}
\hline REACTOR & $\begin{array}{l}\text { TYPE OF CONTROL } \\
\text { POISON }\end{array}$ & $\begin{array}{l}\text { NUMBER } \\
\text { OF CONTROL } \\
\text { ROOS }\end{array}$ & $\begin{array}{l}\text { TYPE OF CONTROL } \\
\text { ROD DRIVE }\end{array}$ & $\begin{array}{l}\text { TOTAL CONTROL } \\
\text { ROD WORTH, \$ }\end{array}$ & $\begin{array}{l}\text { CORE EXCESS } \\
\text { REACTIVITY, } \$\end{array}$ & $\begin{array}{l}\text { EXPECTED TIME } \\
\text { BETWEEN } \\
\text { REFUELING, MO. }\end{array}$ \\
\hline $\begin{array}{l}\text { Hallam Nuclear } \\
\text { Power Facility }\end{array}$ & Gd-Sm Oxides & 19 & $\begin{array}{l}\text { Ba11 Nut, Screw } \\
\text { Magnetic Latch }\end{array}$ & 18.7 & 9.5 & 7 \\
\hline $\begin{array}{l}\text { Sodium Reactor } \\
\text { Experiment }\end{array}$ & $\mathrm{B} \mathrm{Ni}$ & $\begin{array}{l}4 \text { Shim } \\
4 \text { Safety }\end{array}$ & $\begin{array}{l}\text { Ball Nut, Screw } \\
\text { (No Scram) } \\
\text { Link Chain, } \\
\text { Magnetic Latch }\end{array}$ & $\begin{array}{r}11.7 \\
8.8\end{array}$ & 4.0 & $N / A$ \\
\hline $\begin{array}{l}\text { Piqua Nuclear } \\
\text { Power Facility }\end{array}$ & $\mathrm{B}_{4} \mathrm{C}$ & 13 & Magnetic Jack & 16.3 & 11.3 & 4 \\
\hline $\begin{array}{l}\text { Organic Moderated } \\
\text { Reactor Experiment }\end{array}$ & $\mathrm{B}_{4} \mathrm{C}$ & $\begin{array}{l}12 \text { Rods } \\
6 \text { Drives }\end{array}$ & $\begin{array}{l}\text { Rack and Pinion, } \\
\text { Mechanical Latch }\end{array}$ & 21.4 & 10.5 & 6 \\
\hline $\begin{array}{l}\text { Proposed Subsea } \\
\text { Power System }\end{array}$ & $\mathrm{B}_{4} \mathrm{C}$ & $\begin{array}{l}19 \text { Rods } \\
7 \text { Drives }\end{array}$ & Rack and Pinion & 33.5 & 27.2 & 48 \\
\hline
\end{tabular}




\section{APPENDIX 3: ELECTROMAGNETIC PUMP DATA}




\section{BLANK}




\section{ELECTROMAGNETIC PUMPS}

\section{PRINCIPAL SUPPLIERS}

The principal suppliers for AC induction pumps are General Electric, Mine Safety Appliances, and AI. The experience from all three manu-

facturers is recent and directly applicable to the underwater power station.

GE has furnished approximately 60 helical induction electromagnetic pumps during the past 10 years ranging in size from a fraction of a gpm to $300 \mathrm{gpm}$, with developed heads as high as $300 \mathrm{psi}$ and temperatures to $2200 \mathrm{~F}$ (Table II-4). In addition, approximately 25 flat linear induction pumps have been manufactured by GE with capacities to $6500 \mathrm{gpm}$, developed heads to 85 psi, and fluid temperatures to $700^{\circ} \mathrm{F}$. Table II-5 is a list of these pumps.

Table II-6 lists 29 linear induction pumps that have been built by Mine Safety Appliances, and Table II-7 shows AI fabrication and test experience with electromagnetic pumps.

reg: 1214 


\section{Atomics International}

\begin{tabular}{|c|c|c|c|c|c|c|}
\hline \multicolumn{7}{|c|}{$\begin{array}{c}\text { TABLE II-4 } \\
\text { Helical Induction Pumps }\end{array}$} \\
\hline Customer & Qty. & \begin{tabular}{|c|}
$\mathbf{Q}$ \\
$(\mathrm{gpm})$ \\
\end{tabular} & $\begin{array}{c}P \\
\text { (psi) }\end{array}$ & $\begin{array}{c}\mathrm{T} \\
\left({ }^{\circ} E\right) \\
\end{array}$ & Fluid & $\begin{array}{c}\text { Duct } \\
\text { Material } \\
\end{array}$ \\
\hline GE-Vallecito & 2 & 20 & 80 & 1200 & $\mathrm{Na}$ & 304 S. S. \\
\hline GE-Vallecitos & $2^{*}$ & 6 & 20 & $1200^{\circ}$ & $\mathrm{Na}$ & 304 S. S. \\
\hline GE-Vallecitos & $2^{*}$ & 6 & 20 & 1200 & $\mathrm{Na}$ & 304 S. S. \\
\hline GE-Vallecitos & 4 & 6 & 20 & 1200 & $\mathrm{Na}$ & 304 S. S. \\
\hline GE-SPPS & 1 & 4 & 80 & 500 & $\mathrm{Na} / \mathrm{K}$ & 316 S. S. \\
\hline GE-SPPS & $1^{*}$ & 4 & 80 & 500 & $\mathrm{Na} / \mathrm{K}$ & $316 \mathrm{~S} . \mathrm{S}_{\text {. }}$ \\
\hline GE-SPPS & 1 & 3 & 80 & 500 & $\mathrm{NaK}$ & $316 \mathrm{~S} . \mathrm{S}$ \\
\hline GE-NSP & $1^{* *}$ & 3 & 80 & 500 & NaK & \\
\hline Oak Ridge & 1 & .15 & 60 & 1200 & K & 304 S. S. \\
\hline GE-SPPS (NASA) & 1 & 32.8 & 240 & 1000 & $\mathbf{K}$ & $T-111$ \\
\hline GE-NSP & 1 & 5 & 80 & 1200 & $\mathbf{K}$ & 304 S. S. \\
\hline Brookhaven NL & 1 & .0576 & 100 & 1600 & $\mathrm{Na}$ & $\mathrm{Cb}-1 \% \mathrm{Zr}$ \\
\hline AiResearch & 1 & 4 & 120 & 1400 & $\mathbf{K}$ & 316 S.S. \\
\hline GE-SPPS & 1 & 4 & 45 & 1200 & $\mathbf{K}$ & 316 S. S. \\
\hline GE-SPPS & 1 & 5 & 80 & 1500 & $\mathrm{~K}$ & 316 S. S. \\
\hline GE-SPPS & 1 & 3.5 & 100 & 1850 & $\mathrm{Na} / \mathrm{K}$ & Haynes 25 \\
\hline GE-SPPS & 1 & $1.29 / 5$ & $5100 / 20$ & 2200 & $\mathrm{Na} / \mathrm{K}$ & $\mathrm{Cb}-1 \% \mathrm{Zr}$ \\
\hline GE-SPPS & 1 & $1.29 / 5$ & $100 / 20$ & 2200 & $\mathrm{Na} / \mathrm{K}$ & $\mathrm{Cb}-1 \% \mathrm{Z}_{\mathrm{r}}$ \\
\hline GE-SPPS & 1 & $1.29 / 5$ & $5100 / 20$ & 2200 & $\mathrm{Na} / \mathrm{K}$ & $\mathrm{Cb}-1 \% \mathrm{Z}_{x}$ \\
\hline NASA & 1 & 2 & 210 & 1400 & $\mathrm{Ce}_{\mathrm{e}}$ & $\mathrm{Cb}-1 \% \mathrm{Zr}$ \\
\hline NASA & $1^{*}$ & .39 & 66 & 800 & $\mathrm{Ce}$ & 316 S. S. \\
\hline Oak Ridge & 1 & $.158 / .473$ & 200 & 1600 & $\mathrm{~K}$ & $\mathrm{Cb}-1 \% \mathrm{Z} \cdot \mathrm{x}$ \\
\hline AiResearch & 2 & $50 / 10$ & $50 / 115$ & 1400 & $\mathrm{~K}$ & 316 S. S. \\
\hline GE-SPPS & 1 & $.116 / .29$ & $200 / 150$ & 1200 & $\mathrm{~K}$ & $\mathrm{Cb}-1 \% \mathrm{Z}_{x}$ \\
\hline AiResearch & 1 & 10 & 120 & 1400 & $\mathrm{~K}$ & $316 \mathrm{~S} . \mathrm{S}$. \\
\hline GE-APED & 1 & 80 & 30 & 1000 & $\mathrm{Na}$ & 316 S. S. \\
\hline
\end{tabular}

PORM 719-P REV. $8-69$ 
Atomics international

TABLE II-4. Helical Induction Pumps (continued)

\begin{tabular}{|c|c|c|c|c|c|c|}
\hline Custriner & Qty. & $\begin{array}{c}Q \\
(\mathrm{gpm})\end{array}$ & $\begin{array}{c}P \\
(p s i)\end{array}$ & $\begin{array}{c}T \\
(0 F)\end{array}$ & Fluid & $\begin{array}{c}\text { Duct } \\
\text { Material } \\
\end{array}$ \\
\hline JPL & 1 & 0.75 & 270 & 1400 & $\mathrm{Ce}$ & $\mathrm{Cb}-1 \% \mathrm{Zr}$ \\
\hline JPL & 1 & 16 & 270 & 2000 & $\mathrm{Li}$ & $\mathrm{Cb}-1 \% \mathrm{Z}_{\mathrm{r}}$ \\
\hline$A N L$ & 1 & $1.7 / 6.5$ & $100 / \geq 0$ & 2200 & $\mathrm{Na}$ & $\mathrm{Cb}-1 \% \mathrm{Z} \mathbf{x}$ \\
\hline PandW (ORNL) & 2 & 5 & 50 & 2600 & $\mathrm{Li}$ & $\mathrm{Cb}-1 \% \mathrm{Zr}$ \\
\hline Oak Ridge NL & 5 & 30 & 70 & 1500 & $\mathbf{K}$ & 304 S. S. \\
\hline GE-APED & 3 & 25 & 30 & 1050 & $\mathrm{Na}$ & 304 S. S. \\
\hline Aerojet-Gen't. & 1 & 34 & 40 & 1150 & $\mathrm{NaK}$ & $316 \mathrm{~S} . \mathrm{S}$ \\
\hline CNEN (IGE) & 1 & 25 & 200 & 1472 & $\mathrm{Na}$ & $316 \mathrm{~S} . \mathrm{S}$. \\
\hline$G E-\Lambda P E D$ & 1 & $10 / 5$ & $120 / 150$ & 800 & $\mathrm{Na}$ & 316 S. S. \\
\hline GE-BRD & 1 & $15 / 30$ & $150 \ldots$ & 1100 & $\mathrm{Na}$ & $3043_{4}$ \\
\hline GE-SPPS & 1 & 200 & 20 & 1850 & $\mathrm{Na} / \mathrm{K}$ & Haynes 25 \\
\hline GE-SPPS & 1 & 42 & 150 & 1600 & $\mathrm{Na} / \mathrm{K}$ & $310 \mathrm{~S} . \mathrm{S}$. \\
\hline Los Alamos SL & 1 & 500 & 40 & 1100 & $\mathrm{Na}$ & $304 \mathrm{S.S}$ \\
\hline Aireseazch & 1 & 150 & 50 & 1800 & $\mathrm{Na}$ & Haynes 25 \\
\hline NASA & 1 & 80 & 30 & 2000 & $\mathrm{Na}$ & $\mathrm{Cb}-1 \% \mathrm{Zr}$ \\
\hline Airescarcis & $* * *$ & 210 & 35 & 1000 & $K$ & 374 S. S. \\
\hline CE-APED & 1 & $20 / 250$ & $50 / 12$ & 1050 & $\mathrm{Na}$ & 304 S. S. \\
\hline GE-APED & 1 & 250 & 30 & 1050 & $\mathrm{Na}$ & 304 S. S. \\
\hline GE-SPPS & 1 & 85 & 75 & 2200 & $\top_{i}$ & $\mathrm{~T}-111$ \\
\hline GE-SPPS & 1 & 5 & 300 & 2000 & $K$ & $T-111$ \\
\hline GE-SFPS & 1 & 160 & 70 & 1400 & $\mathrm{VaK}$ & $321 S . S_{0}$ \\
\hline GE-SPPS & 1 & 160 & 70 & 2400 & Nart & $-\infty$ \\
\hline
\end{tabular}

* Duct oniy

* Siator Cnly

** Design Only 


\section{Atomics International}

TABLE II-4. Helical Induction Pumps (continued)

\begin{tabular}{l|l|l|l|l|l|l} 
Customer & Qty. & $\begin{array}{c}Q \\
(\mathrm{gpm})\end{array}$ & $\begin{array}{c}\mathrm{P} \\
(\mathrm{psi})\end{array}$ & $\begin{array}{c}\mathrm{T} \\
\left({ }^{\circ} \mathrm{F}\right)\end{array}$ & Fluid & $\begin{array}{c}\text { Duct } \\
\text { Material }\end{array}$ \\
\hline GE-BRD & 1 & 200 & 125 & 800 & $\mathrm{Na}$ & $304 \mathrm{~S} . \mathrm{S}_{0}$ \\
GE-BRD & 1 & $200 / 300$ & 130 & $1100 /$ & $\mathrm{Na}$ & $304 \mathrm{~S} . \mathrm{S}_{0}$ \\
& \multirow{3}{*}{ AI } & 318 & 310 & 1000 & $\mathrm{Na}$ & $316 \mathrm{S.S}$
\end{tabular}

Table II -5

Flat Linear Induction Pumps

\begin{tabular}{|c|c|c|c|c|c|c|}
\hline Customer & Qty. & $\begin{array}{c}Q \\
(\mathrm{gpm})\end{array}$ & $\begin{array}{c}\mathrm{P} \\
(\mathrm{psi})\end{array}$ & $\begin{array}{c}T \\
(\cdot F)\end{array}$ & Fluid & $\begin{array}{c}\text { Duct } \\
\text { Material }\end{array}$ \\
\hline KAPL & 2 & 60 & 30 & 700 & $\mathrm{Na}$ & 347 S. S. \\
\hline KAPL & 2 & 1200 & 38 & 700 & $\mathrm{Na}$ & 347 S. S. \\
\hline $\operatorname{KAPL}(\operatorname{Mark} A)$ & 9 & 3000 & 75 & 580 & $\mathrm{Na}$ & 347 S. S. \\
\hline KAPL (Mark B) & 8 & 3300 & 85 & 580 & $\mathrm{Na}$ & 347 S. S. \\
\hline LASL & 2 & \multicolumn{4}{|c|}{ Modification of 2 Mark A pumps } & \\
\hline Pratt \& Whit. & $t+$ & 145 & 20 & 1000 & $\mathrm{Na}$ & 315 S. S. \\
\hline Argonne Nat'l. & 1 & 5000 & 40 & 700 & $\mathrm{Na}$ & 347 S. S. \\
\hline GE-APED & 2 & 5000 & 38 & 700 & $\mathrm{Na}$ & 304 S. S. \\
\hline Argonne Nat'l. & 1 & 6500 & 53 & 700 & $\mathrm{Na}$ & 347 S. S. \\
\hline Argonne Nat'l. & 1 & 6500 & 53 & 590 & $\mathrm{Na}$ & 304 S. S. \\
\hline Alleg. Lud. & 1 & 150 & 25 & 2800 & Steel & Ceramic \\
\hline
\end{tabular}

t† Derign Study Only

FORM 719-P REV, 8-69 
TABLE II-7

AI ELECTROMAGNETIC PUMP EXPERIENCE

\begin{tabular}{|c|c|c|c|c|c|c|}
\hline $\begin{array}{c}\text { Pump } \\
\text { Designation }\end{array}$ & Pump Type & $\begin{array}{l}\text { Number } \\
\text { Fabricated }\end{array}$ & $\begin{array}{l}\text { Number } \\
\text { Tested }\end{array}$ & $\begin{array}{l}\text { Maximum } \\
\text { Fluid } \\
\text { Temper- } \\
\text { ature } \\
\left({ }^{\circ} \mathrm{F}\right)\end{array}$ & $\begin{array}{l}\text { Maximum } \\
\text { (hr/unit) }\end{array}$ & $\begin{array}{c}\text { Total } \\
\text { (unit=hr) }\end{array}$ \\
\hline SNAP 10A & $\begin{array}{l}\text { de thermoelectric } \\
\text { conduction }\end{array}$ & 41 & 41. & 1050 & 20,000 & 194,000 \\
\hline SNAP 2 & $\begin{array}{l}\text { de thermoelectric } \\
\text { conduction }\end{array}$ & 12 & 12 & 1200 & 6,100 & 28,000 \\
\hline SNAP 8 & ac induction & 4 & 4 & 1350 & $\sim 8,000$ & $\sim 32,000$ \\
\hline Test Loop & de conduction & $>50$ & $>50$ & 1400 & $\sim 25,000$ & $>200,000$ \\
\hline Triple Pas & de conduction & 1 & 1 & 1000 & 100 & 100 \\
\hline Sodium & ac induction & $>25$ & $>25$ & 1350 & $>50,000$ & $\sim 250,000$ \\
\hline Special & dc induction & 4 & 4 & 1000 & $\sim 500$ & $\sim 1,000$ \\
\hline FFTE, L-30 & ac induction & 5 & & 1000 & & \\
\hline FFTF, L-100 & ac induction & 8 & & 1100 & & \\
\hline FFTF, L-200 & ac induction & 2 & & 700 & & \\
\hline & Grand Total & $>152$ & & & & $>490,100$ \\
\hline
\end{tabular}




\section{BLANK}




\section{APPENDIX 4: Al's PROPOSED REFUELING BASE}

Arthur D Little, Inc. 
BLANK 
Atomics International Division

8900 De Soto Avenue

Canoga Park, California 91304

(213) $341-1000$

January 20, 1977

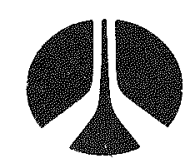

Rockwell

International

In reply refer to 77AT-467

Dr. John J. Bzura

Arthur D. Little, Inc.

Acorn Park

Cambridge, Massachusetts 02140

Dear Dr. Bzura:

The enclosures to this letter provide the information you requested on estimated costs for the base site facilities required for refueling and refurbishing subsea nuclear power generating stations.

Two preliminary estimates are presented, based on two different conceptual approaches to the potential facility and equipment requirements for the refueling and refurbishment operations.

The Case I estimates are based on locating the base site in a protected harbor region, where no additional sea walls or other protective measures are required to shield the dock-side areas of the base site from effects of adjoining waters. Case I is also based on the use of procedures for refueling and refurbishment which do not require removing the reactor module and the generator module from the barge. This approach will entail the removal of some components from the modules (pressure vesseis) and the refurbishment of other components in situ rather than in shop areas. Should the removal of the pressure vessels become necessary at infrequent intervals, this would be accomplished by means of mobile cranes of the necessary capacity, rented or leased as required.

The Case II estimates are based on locating the base site in an open coastal region or other location where some protective measures are required; estimated costs of a sea wall or breakwater and the associated "lagoon" area are included. Also, in this case, the refurbishment approach is to remove the reactor module and the generator module from the barge and transfer these large pressure vessels to shop areas for refurbishment operations. This results in larger area requirements in many sections of the facility, as well as a large capacity crane.

The Case I and Case II estimates should provide a representative range of estimated costs for a suitable base site facility in the absence of the identification of a specific site. 
77AT-467

January 20, 1977

Page 2

The enclosures include layout sketches of the two conceptual base site facilities and breakdowns of the principal cost elements. The last two pages show an estimate of the manpower requirements for the facility and a computation of annual facility amortization and operating costs. A comparison of these annual costs to the refurbishment costs employed in the AI-LPS study indicates that a throughput of 3 to 4 subsea systems per year would make the base site Facility a viable operation. This rate appears reasonable in view of the refurbishment operations currently anticipated.

Very truiy yours,

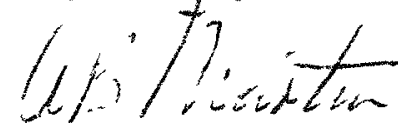

A. B. Martin

Program Manager

Advanced Nuclear Systems

Atomic International Division

jdj :4/1-2

Enclosures as noted

cc w/enclosures:

Mr. N. Gerstein, ERDA-WASH

Mr. W. von Flue, ERDA-SAN

Mr. F. Glaski, ERDA-LA 


\section{BASE SITE CONCEPTUAL COST ESTIMATE}

(CASE I)

Facility

Electrical

Systems

Site Grading

Security

Equipment

Subtotal

Engineering (Design plus Field) 20\%

Subtotal

Contingency $20 \%$

\begin{tabular}{|c|c|}
\hline & $\begin{array}{r}\$ 2,185,000 \\
500,000 \\
1,000,000 \\
200,000 \\
300,000 \\
3,455,000 \\
\end{array}$ \\
\hline Subtotal & $\begin{array}{r}\$ 7,640,000 \\
1,528,000 \\
\end{array}$ \\
\hline Subtotal & $\begin{array}{r}9,168,000 \\
1,833,000 \\
\end{array}$ \\
\hline Total & $\$ 11,001,000$ \\
\hline
\end{tabular}

sur:118 


$\begin{array}{lrr}\text { Administration Area } & 3,500 & 175,000 \\ \text { Repair Area } & 5,625 & 365,625 \\ \text { Machine Shop } & 5,000 & 250,000 \\ \text { Hot Machine Shop } & 1,610 & 80,500 \\ \text { Dry Dock } & 12,000 & 780,000 \\ \text { New Fue1 Control } & 720 & 36,000 \\ \text { Operating Personnel Control } & 660 & 33,000 \\ \text { R/A Waste \& Spent Fuel Vault } & 1,524 & 76,000 \\ \text { New Fuel Storage Vault } & 1,400 & 70,000 \\ \text { New Fuel \& Core Assembly } & 1,368 & 68,400 \\ \text { Operating Gallery } & 1,360 & 36,000 \\ \text { Hot Ce11 } & 700 & 136,800 \\ \text { Corridor } & 36,199 & 7,100 \\ & & 2,114,425 \\ & 1,875 & 10,000 \\ \text { Machine Shop Dock } & 1,500 & 8,000 \\ \text { R/A Shipping Dock } & 3,750 & 18,750 \\ \text { Wharf Side Repair Area } & 6,750 & 33,750 \\ \text { Wharf Side Repair Area } & 13,875 & 70,500 \\ & & 2,184,925\end{array}$

Based on moderately rough terrain and sandy soil.

svr: 118 
Sub-Stations (3)

Site \& Facility Lighting

150,000

320,000

Utility to Sub-Station

30,000

500,000

Based on transmission line not being over 5 miles distance.

svr: 118 
R/A Exhaust System

R/A Drain/Hold Tank System

Liquid Nitrogen System

Argon System

Shop Air Control System

Air Conditioning System

Communications-Tel/PA System

Fire Suppression System

R/A NaK Handling System

Toluene Handling System

Cooling Water system

Compressed Air System

Dry Dock Dewatering System

Personnel Life Support System

X-Ray Dark Room, Film DVL. System

Domestic Water System

Domestic Sewer System

Process Heating System

R/A Monitoring/Control System

$\begin{array}{r}\$ \\ \hline 100,000 \\ 40,000 \\ 50,000 \\ 20,000 \\ 20,000 \\ 125,000 \\ 50,000 \\ 180,000 \\ 100,000 \\ 25,000 \\ 12,000 \\ 15,000 \\ 50,000 \\ 50,000 \\ 50,000 \\ 8,000 \\ 8,000 \\ 60,000 \\ 40,000 \\ \hline 1,000,000\end{array}$

sur: 118 
Based on moderately rough terrain, sandy soil, and access road being within 5 miles of a main highway. 


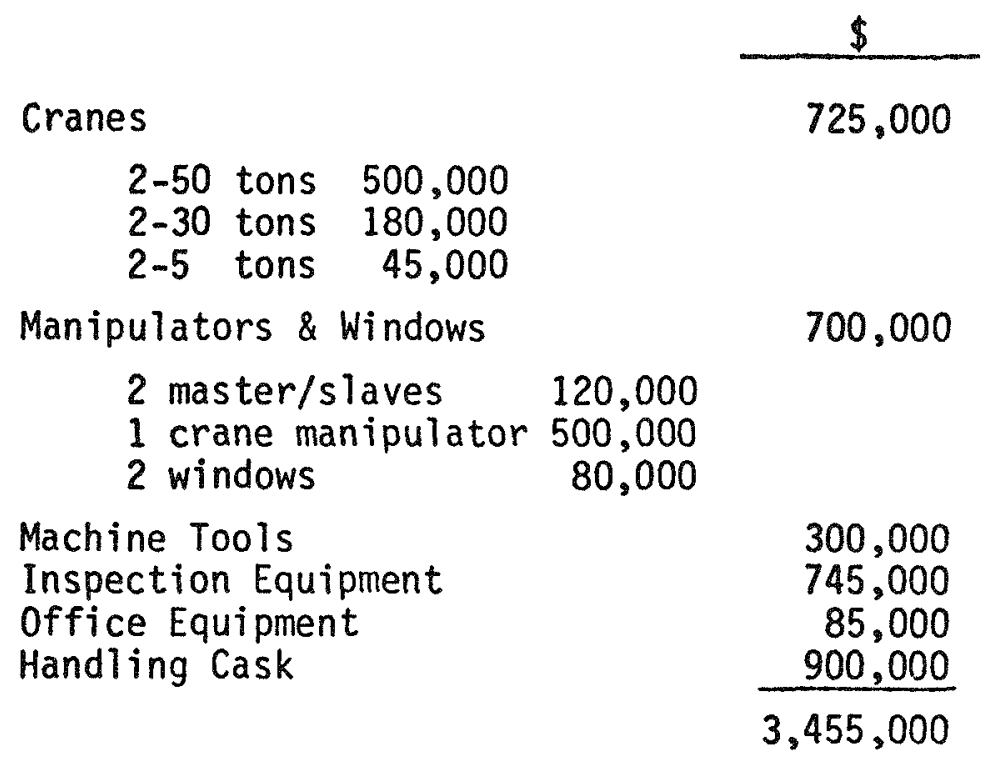

svr: 118 


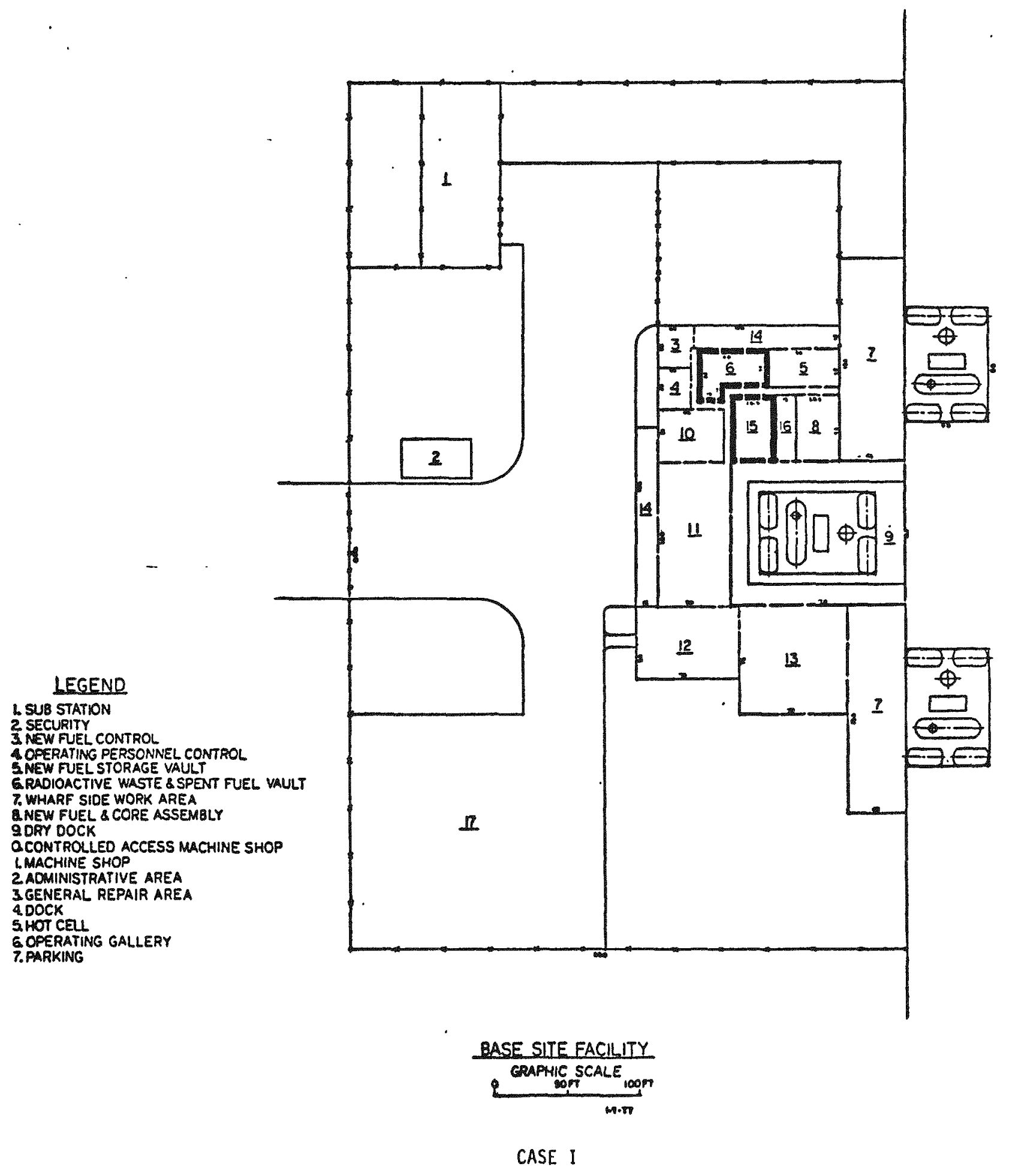


Facility

Electircal

Systems

Site Grading

Lagoon

Security

Equipment

Engineering (Design plus Field) $20 \%$

Contingency $20 \%$

\begin{tabular}{|c|c|}
\hline & $\begin{array}{r}\$ 6,400,000 \\
600,000 \\
1,355,000 \\
250,000 \\
1,500,000 \\
350,000 \\
4,400,000 \\
\end{array}$ \\
\hline Subtotal & $\begin{array}{r}\$ 14,855,000 \\
2,971,000 \\
\end{array}$ \\
\hline Subtotal & $\begin{array}{r}\$ 17,826,000 \\
3,565,200 \\
\end{array}$ \\
\hline Total & $\$ 21,391,200$ \\
\hline
\end{tabular}

$\$ 6,400,000$

600,000

250,000

$, 500,000$

350,000

$14,855,000$

$\$ 17,826,000$

$\$ 21,391,200$

svr: 118 


\begin{tabular}{lrr} 
& \multicolumn{1}{c}{$\mathrm{FT}^{2}$} & \multicolumn{1}{c}{$\$$} \\
\cline { 2 - 3 } Administration Area & 6,000 & 300,000 \\
Machine Shop & 16,800 & 840,000 \\
Controlled Access Shop & 7,000 & 350,000 \\
Operating Personnel Control & 2,100 & 105,000 \\
New Fuel Control & 2,100 & 105,000 \\
New Fuel \& Core Assembly & 2,900 & 145,000 \\
New Fuel Storage & 2,900 & 145,000 \\
Hot Cell & 3,700 & 370,000 \\
R/A Waste \& Spent Fuel Storage & 3,700 & 314,000 \\
Generator Module Room & 15,000 & $1,063,000$ \\
Dry Dock Room & 19,500 & $1,657,500$ \\
Reactor Module Room & 8,100 & 810,000 \\
Operating Gallery & 2,272 & 113,600 \\
& 92,072 & $6,318,100$ \\
& & \\
Machine Shop Dock & 6,000 & 34,500 \\
New Fuel \& R/A Waste & 3,480 & 17,400 \\
Shipment Dock & 5,900 & 29,500 \\
Equipment Pad & 16,280 & 81,400 \\
& &
\end{tabular}

svr: 118 
Sub-Stations (3)

Site/Facility Lighting

Utility to Sub-Station
$\$$

150,000

420,000

30,000

600,000

svr: 118 
R/A Exhaust System

R/A Drain/Hold Tank System

Liquid Nitrogen System

Argon System

Shop Air Control System

Air Conditioning System

Communications-Tel/PA System

Fire Suppression System

R/A NaK Handling System

Toluene Handling System

Cooling Water System

Compressed Air System

Dry Dock Dewatering System

Personnel Life Support System

X-Ray Dark Room, Film DVL System

Domestic Water System

Domestic Sewer System

Process Heating System

$R / A$ Monitoring/Control System

$\begin{array}{r}\$ \\ \hline 200,000 \\ 50,000 \\ 50,000 \\ 20,000 \\ 25,000 \\ 250,000 \\ 55,000 \\ 200,000 \\ 100,000 \\ 20,000 \\ 25,000 \\ 15,000 \\ 50,000 \\ 50,000 \\ 100,000 \\ 10,000 \\ 10,000 \\ 75,000 \\ 50,000 \\ \hline 1,355,000\end{array}$

sur: 118 
Based on moderately rough terrain, sandy soil, and access road being within 5 miles of a main highway.

svr: 118 
Based on moderately rough terrain and sandy soil. Also the length of the channel from the ocean and any backwater that may be required were not included in this estimate. 
Cranes

$$
\begin{array}{lrr}
1-250 & \text { tons } & 840,000 \\
2-50 & \text { tons } & 500,000 \\
2-30 & \text { tons } & 180,000 \\
2-5 & \text { tons } & 50,000
\end{array}
$$

Manipulators \& Windows

3 master/slaves

1 powered crane

3 lead windows

180,000

500,000

120,000

Machine Tools

Inspection Equipment

Office Equipment

Handling Cask

$$
\begin{array}{r}
\$ \\
\hline 1,570,000 \\
800,000 \\
\\
300,000 \\
745,000 \\
85,000 \\
900,000 \\
\hline 4,400,000
\end{array}
$$

svr: 118 


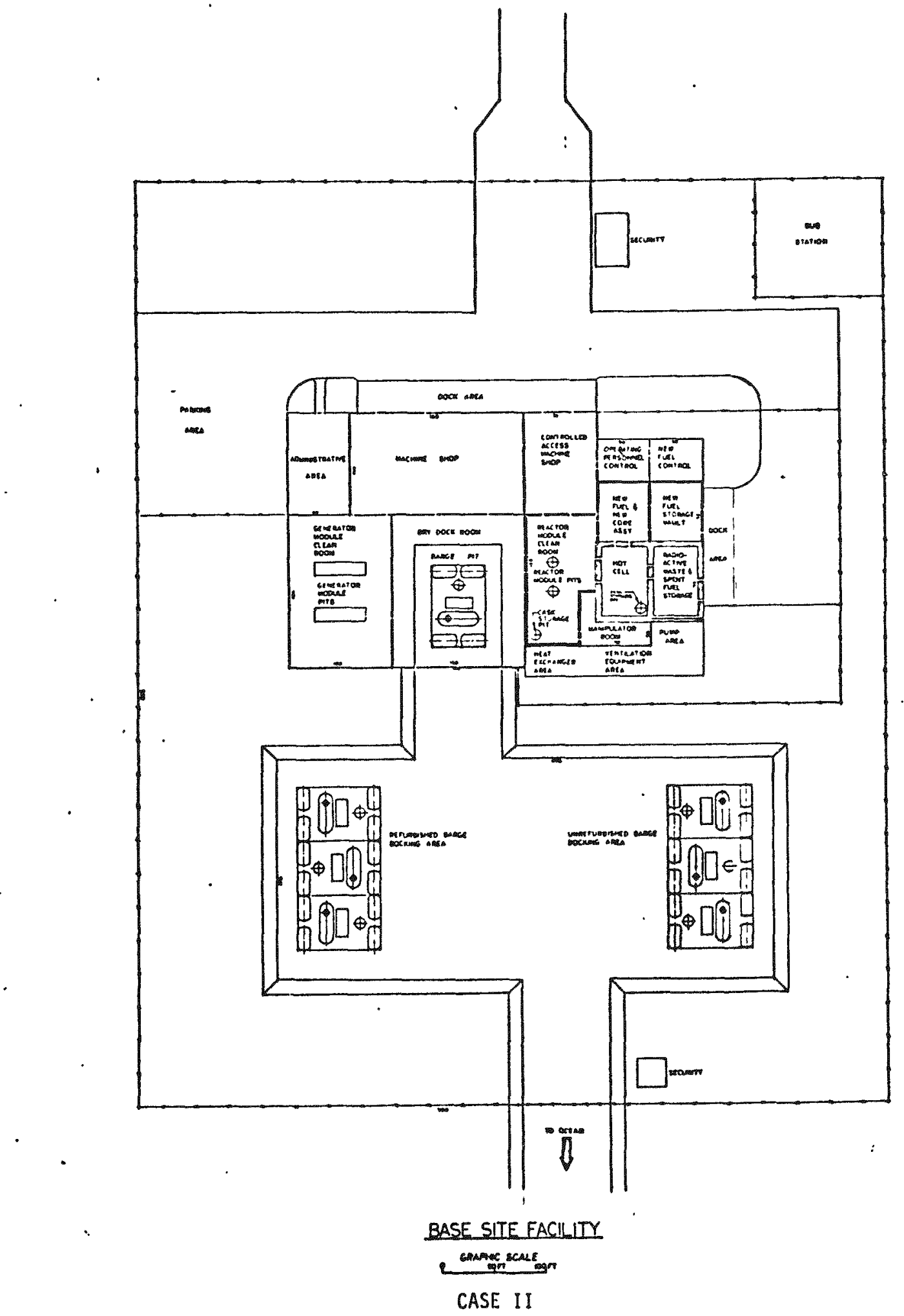


BASE SITE FACILITY PERSONNEL

CATEGORY

NUMBER

Plant Manager

1

Chief Engineer

1

Engineers

Health Physicist \& Nuclear Mat' Is Mgmt

2

Planners

Secretaries

Machinist - General

Machinist - Hot Shop

Mechanics - General

Mechanics - Specialist

Mechanics - Hot Shop

Security Guards

Firemen

2

2

22 - Direct Classifications

16 - Indirect Classifications

svr:118 
BASE SITE ANNUAL

FACILITY AND OPERATING COSTS

$(\$ 000)$

CASE I CASE II

Amortization

Capital ( 30 years)

Equipment (10 years)

200

501

$500 \quad 634$

Operating (Payroll)

$\frac{1,200}{1,900} \quad \frac{1,200}{2,335}$

Profit (20\%)

$\frac{380}{2,280} \quad \frac{465}{2,800}$

svr: 118 
BLANK 


\section{APPENDIX 5: POWER SUPPLY COST BREAKDOWN}

Scenario A: $3-1800 \mathrm{~kW}$ turbines and a 40-mile dc cable system

\begin{tabular}{lr} 
Cable alone & $\$ 3.52 \times 10^{6}$ \\
Cable installation & $1.92 \times 10^{6}$ \\
Terminals & $1.16 \times 10^{6}$ \\
Turbines & $.99 \times 10^{6}$ \\
Turbine installation & $.15 \times 10^{6}$ \\
\multicolumn{1}{c}{ Total installed cost } & $\$ 7.74 \times 10^{6}$
\end{tabular}

Maintenance cost: $3.2 \times 10^{3} \mathrm{~kW} \times 8760 \mathrm{hrs} \times 3.5 \times 10^{-3} \$ / \mathrm{kWh}=\$ 98,000$

Fuel cost: $4 \times 2.8 \times 10^{7} \mathrm{kWh} \times 3412 \mathrm{Btu} / \mathrm{kWh} \times \$ 2.24 \times 10^{-6}=\$ 856,000$

Total annual cost

$=\$ 954,000$

Scenario B: $2-3500 \mathrm{kVA}$ transformers and a 40-mile dc cable system

\begin{tabular}{lr} 
Cable alone & $\$ 3.52 \times 10^{6}$ \\
Cable installation & $2.40 \times 10^{6}$ \\
ac substation & $.11 \times 10^{6}$ \\
dc terminals & $1.16 \times 10^{6}$ \\
\multicolumn{1}{c}{ Total installed cost } & $\$ 7.19 \times 10^{6}$
\end{tabular}

Operating cost: $2.8 \times 10^{7} \mathrm{kWh} \times \$ .03 / \mathrm{kWh}=\$ 840,000$ 


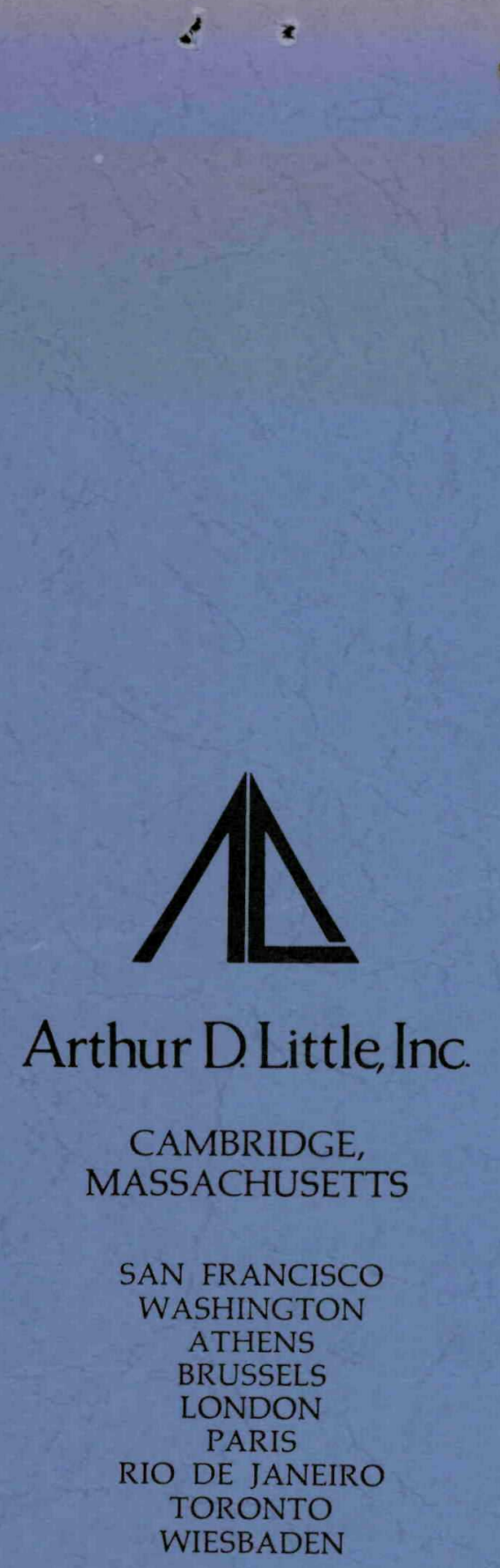

